\title{
E6-mediated activation of JNK drives EGFR signalling to promote proliferation and viral oncoprotein expression in cervical cancer
}

\author{
Ethan L. Morgan $\mathbb{1}^{1,2,3} \cdot$ James A. Scarth $\mathbb{1}^{1,2} \cdot$ Molly R. Patterson $\mathbb{1}^{1,2} \cdot$ Christopher W. Wasson $\mathbb{1}^{1,4}$. \\ Georgia C. Hemingway ${ }^{1} \cdot$ Diego Barba-Moreno ${ }^{1,2} \cdot$ Andrew Macdonald $\mathbb{I}^{1,2}$
}

Received: 29 May 2020 / Revised: 16 November 2020 / Accepted: 18 November 2020 / Published online: 10 December 2020

(c) The Author(s) 2021. This article is published with open access

\begin{abstract}
Human papillomaviruses (HPV) are a major cause of malignancy worldwide, contributing to $~ 5 \%$ of all human cancers including almost all cases of cervical cancer and a growing number of ano-genital and oral cancers. HPV-induced malignancy is primarily driven by the viral oncogenes, E6 and E7, which manipulate host cellular pathways to increase cell proliferation and enhance cell survival, ultimately predisposing infected cells to malignant transformation. Consequently, a more detailed understanding of viral-host interactions in HPV-associated disease offers the potential to identify novel therapeutic targets. Here, we identify that the c-Jun N-terminal kinase (JNK) signalling pathway is activated in cervical disease and in cervical cancer. The HPV E6 oncogene induces JNK1/2 phosphorylation in a manner that requires the E6 PDZ binding motif. We show that blockade of JNK1/2 signalling using small molecule inhibitors, or knockdown of the canonical JNK substrate c-Jun, reduces cell proliferation and induces apoptosis in cervical cancer cells. We further demonstrate that this phenotype is at least partially driven by JNK-dependent activation of EGFR signalling via increased expression of EGFR and the EGFR ligands EGF and HB-EGF. JNK/c-Jun signalling promoted the invasive potential of cervical cancer cells and was required for the expression of the epithelial to mesenchymal transition (EMT)-associated transcription factor Slug and the mesenchymal marker Vimentin. Furthermore, JNK/c-Jun signalling is required for the constitutive expression of HPV E6 and E7, which are essential for cervical cancer cell growth and survival. Together, these data demonstrate a positive feedback loop between the EGFR signalling pathway and HPV E6/E7 expression, identifying a regulatory mechanism in which HPV drives EGFR signalling to promote proliferation, survival and EMT. Thus, our study has identified a novel therapeutic target that may be beneficial for the treatment of cervical cancer.
\end{abstract}

Edited by G. Melino

Supplementary information The online version of this article (https:// doi.org/10.1038/s41418-020-00693-9) contains supplementary material, which is available to authorized users.

Ethan L. Morgan

ethan.morgan@nih.gov

$\triangle$ Andrew Macdonald

a.macdonald@leeds.ac.uk

1 School of Molecular and Cellular Biology, Faculty of Biological Sciences, University of Leeds, Leeds, West Yorkshire LS2 9JT, UK

2 Astbury Centre for Structural Molecular Biology, University of Leeds, Leeds, West Yorkshire LS2 9JT, UK

3 Present address: Tumor Biology Section, Head and Neck Surgery Branch, National Institute of Deafness and Other Communication Disorders, National Institute of Health, Bethesda, MD, USA

4 Present address: Leeds Institute of Rheumatic and Musculoskeletal Medicine, School of Medicine, University of Leeds, St-James University Teaching Hospital, Leeds, West Yorkshire, UK

\section{Introduction}

Persistent infection with human papillomavirus (HPV) is the underlying cause of most cervical cancers and several other anogenital and oropharngeal cancers [1]. These cancers are predominantly caused by HPV16 and HPV18; however, 13 other high-risk HPV types are also associated with cancer development [2]. HPV-induced transformation is primarily driven by three virus-expressed oncogenes: E5, E6 and E7. HPV E5 functions as an ion channel, induces EGFR signalling and promotes resistance to anti-PD-L1 immunotherapy [3-6]. E6 and E7 are the primary drivers of viral oncogenesis; in addition to their well-characterised inactivation of the $\mathrm{p} 53$ and $\mathrm{pRb}$ tumour suppressors [7, 8], they regulate a multitude of signalling pathways that contribute to transformation [9-15].

Mitogen-activated protein kinases (MAPK) convert extracellular stimuli into a range of cellular responses [16]. 
The MAPKs extracellular signal-regulated kinase (ERK) and p38 have been shown to have important roles in the HPV life cycle and in HPV-induced transformation [1719]. In contrast, less is known about the role of the c-Jun Nterminal kinases (JNK).

JNKs consist of 10 isoforms, generated via alternative splicing from three genes: $J N K 1$ and $J N K 2$ (four isoforms of each) are ubiquitously expressed, whereas JNK3 (two isoforms) is mainly expressed in the brain, heart and testes [20]. JNK signalling can regulate tumour suppressive and oncogenic functions [21]. In combination with oncogenic Ras, JNK can either suppress or promote oncogenesis [2224]. JNK can also promote malignancy in combination with PTEN loss or expression of the BCR-Abl oncogene $[25,26]$. Interestingly, JNK1 and JNK2 can have opposing roles during tumour development, making JNK signalling not only complex but also tissue-type specific $[27,28]$.

We previously observed increased JNK1/2 phosphorylation in primary normal human keratinocytes (NHK) stably harbouring the HPV18 genome [29]; however, it is not known if JNK contributes to transformation in HPVassociated cancers. In this study, we demonstrate that phosphorylation of $\mathrm{JNK} 1 / 2$ and its substrate c-Jun is enhanced in HPV+ cervical cancer. We show that JNK1/ 2 signalling is critical for the proliferative and invasive properties of cervical cancer cells and is required for basal and growth factor-induced viral oncogene expression. Together, we identify a host signalling pathway that plays a key role in cervical cancer progression that could potentially serve as a therapeutic target for HPV-associated cancers.

\section{Results}

\section{c-Jun N-terminal kinase 1/2 (JNK1/2) phosphorylation is increased in cervical cancer}

We have published that JNK1/2 phosphorylation is increased in NHKs containing the HPV18 genome when compared to donor-matched control primary cells ([29]; Fig. 1A). We therefore investigated the role of JNK signalling in HPV-associated disease. JNK1/2 phosphorylation was analysed in cytology samples from a cohort of HPV16+ patients with cervical intraepithelial neoplasia (CIN); CIN1 represents a transient HPV infection with mild dysplasia, while CIN3 represents severe dysplasia [30]. Cytology samples from healthy, HPV-negative (HPV-) patients were used as controls. JNK1/2 phosphorylation increased during progression through CIN1 to CIN3, whilst total JNK1/2 expression remained constant (Fig. 1B; quantified in Fig. 1C). We next examined JNK1/2 phosphorylation in a panel of cervical cancer cell lines. Compared to NHKs, JNK1/2 phosphorylation was higher in all cervical cancer cells and was highest of all in HPV-positive (HPV+) cells (Fig. 1D). To determine if this extended to cervical cancer tissue, we performed immunohistochemistry (IHC) on a cervical cancer tissue microarray (TMA). JNK1/2 phosphorylation was significantly higher in the cervical cancer tissue when compared to control tissue (Fig. 1E). These data demonstrate that JNK1/2 phosphorylation is increased during cervical disease progression and in cervical cancer.

\section{JNK1/2 are required for C-Jun/AP-1 activity in cervical cancer}

JNKs accomplish many of their functions by phosphorylating and activating Activator Protein-1 (AP-1) transcription factors [31]. We focused on Jun proteins, as these are commonly associated with tumourigenesis, particularly in cancers arising from keratinocytes, and c-Jun is a major cellular substrate of JNK $[32,33]$. We observed increased cJun and JunD transcript and protein levels in HPV18 containing keratinocytes (Supplementary Fig. 1A, B). This increase was also seen in HPV + cancer cells (Supplementary Fig 1C, D). In contrast, JUNB expression was unchanged (Supplementary Fig. 1A and C). Finally, using data from The Cancer Genome Atlas (TCGA), we observed that JUN expression significantly correlated with reduced survival in cervical cancer patients, whereas JUND expression did not (Supplementary Fig. 1E). We therefore focused on c-Jun as a potential downstream target of JNK1/ 2 in subsequent studies.

The transcriptional activity of c-Jun is regulated by Ser63/Ser73 phosphorylation [34]. ERK, JNK and p38 are all reported to phosphorylate these sites [34-36]. Using a reverse-phase protein array (RPPA) data set [37, 38], phosphorylation of ERK1/2 and JNK1/2, but not p38, significantly correlated with c-Jun phosphorylation in cervical cancer (Fig. 2A). To validate this, we used specific inhibitors targetting MEK1/2 (which inhibits ERK1/2), JNK1/2 and p38 and assessed c-Jun phosphorylation. Inhibition of p38 had no effect on c-Jun phosphorylation, whilst ERK1/2 inhibition led to a small $(\sim 30 \%)$ decrease in c-Jun phosphorylation. Crucially, inhibition of JNK1/2 using two chemically distinct inhibitors resulted in a $70 \%$ and $\sim 90 \%$ reduction, suggesting that JNK1/2 are the primary kinases required for c-Jun phosphorylation in HPV + cervical cancer cells (Fig. 2B). Pharmacological inhibition of JNK1/2 also resulted in a $\sim 75 \%$ reduction in AP-1 transcriptional activity (Fig. 2C). To investigate if c-Jun was required for AP-1 signalling in these cells, we depleted c-Jun expression which resulted in a $\sim 50 \%$ reduction in AP-1 activity (Fig. 2D). Over-expression of c-Jun resulted in a $\sim 2.5$-fold increase in AP-1 activity (Fig. 2E), together suggesting that JNK/c-Jun signalling drives AP-1 activity in HPV+ cervical cancer cells. 

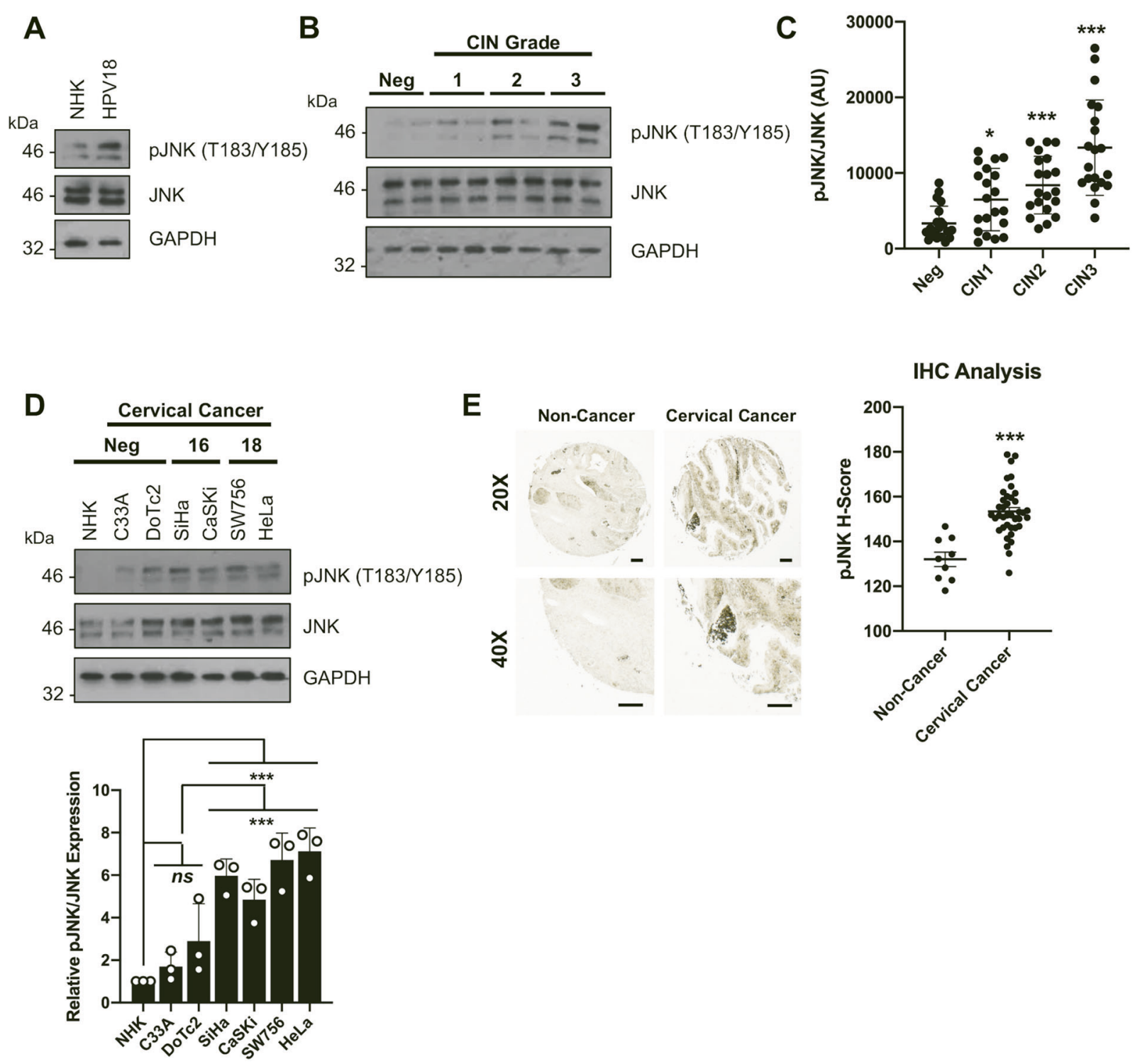

Fig. 1 c-Jun $\mathrm{N}$-terminal kinases are significantly phosphorylated in HPV + cervical cancer. A Representative western blot of normal human keratinocytes (NHK) and NHKs containing the HPV18 genome (HPV18) analysed for phosphorylated JNK1/2 and total JNK expression. GAPDH served as a loading control. Data shown are representative of at least three independent experiments. B Representative western blot from cytology samples of CIN lesions of increasing grade analysed for phosphorylated JNK1/2 and total JNK expression. GAPDH served as a loading control. C Scatter plot of densitometry analysis of a panel of cytology samples. Twenty samples from each clinical grade (Neg, CIN 1-3) were analysed by western blot and densitometry analysis was performed for phosphorylated JNK1/2 and total JNK expression. D Representative western blot analysis of a panel of six cervical cancer cell lines-two HPV - (C33A and DoTc2 4510), two HPV16+ (SiHa and CaSKi) and HPV18+

\section{HPV E6 induces JNK1/2 phosphorylation via the PDZ-binding motif (PBM)}

Expression of HPV18 E6 in C33A cells and NHKs increased JNK1/2 phosphorylation (Fig. 3A), whilst E7
(SW756 and HeLa)—and NHK cells for phosphorylated JNK1/2 and total JNK. GAPDH served as a loading control. Densitometry analysis of phosphorylated JNK1/2, normalised to total JNK and GAPDH expression, from three independent experiments is shown below. E Representative results of immunohistochemical staining for phosphorylated JNK1/2 expression in cervical cancer tissues and adjacent non-tumour tissues. Images were acquired using identical exposure times. Scale bar, $50 \mu \mathrm{m}$. Statistical analysis for phosphorylated JNK1/2 expression in cervical cancer tissues $(n=39)$ compared with nontumour tissues $(n=9)$ is shown on the right. Each section was stained and analysed in duplicate. Phosphorylated JNK1/2 was quantified in an automated fashion using the IHC Profiler Plug-in for ImageJ. Error bars represent the mean $+/-$ standard deviation. $* P<0.05$, $* * P<$ $0.01, * * * P<0.001$ (Student's $t$-test).

expression only slightly increased JNK1/2 phosphorylation and did not significantly enhance JNK1/2 phosphorylation when co-expressed with E6. Further, depletion of endogenous E6/E7 by siRNA reduced the level of JNK1/2 phosphorylation in both HeLa and CaSKi cells (Fig. 3B). 
A
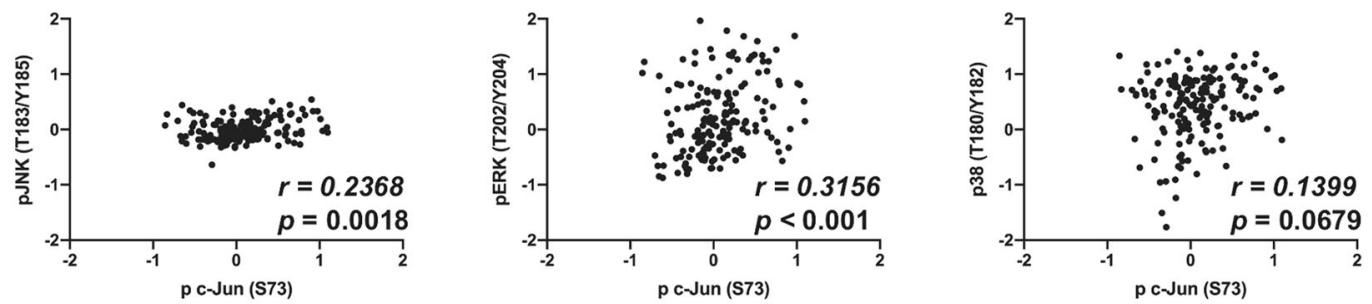

B

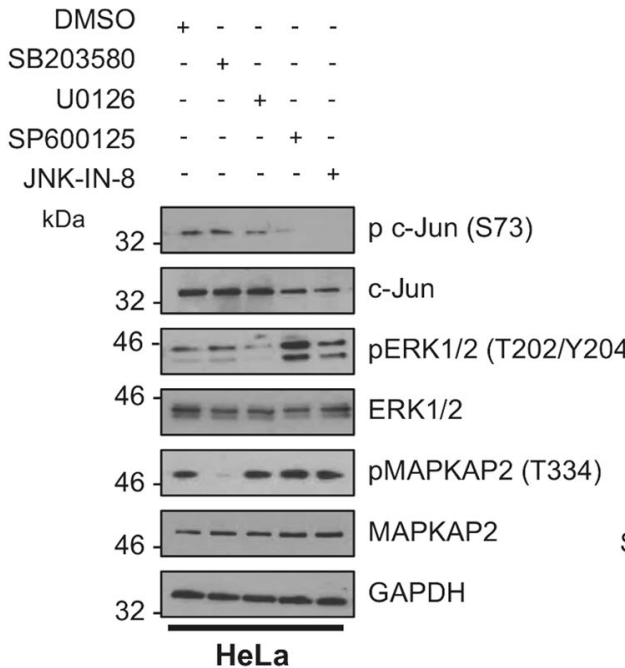

C

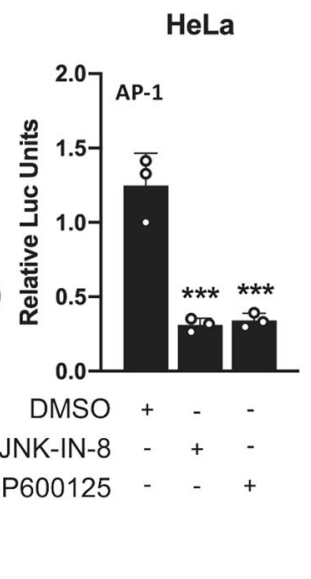

D

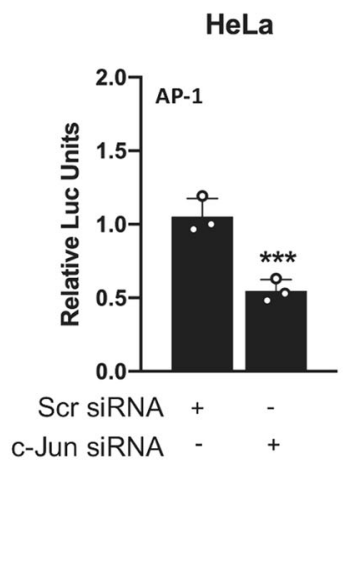

$E$
Fig. 2 JNK activity is required for c-Jun/AP-1 activity in cervical cancer. A Scatter plot of expression levels of c-Jun phosphorylation and JNK phosphorylation, ERK phosphorylation and p38 phosphorylation as analysed using the MD Anderson public RPPA data set. The correlation coefficient $(r)$ was calculated using Spearman's rank analysis. B Representative western blot of HeLa cells treated with the p38 inhibitor SB203580 $(10 \mu \mathrm{M})$, the MEK1/2 inhibitor U0126 $(10 \mu \mathrm{M})$, or the JNK inhibitors SP600125 $(10 \mu \mathrm{M})$ and JNK-IN-8 $(3 \mu \mathrm{M})$. Lysates were analysed for phosphorylated and total c-Jun, phosphorylated and total ERK and phosphorylated and total MAPKAP2. GAPDH served as a loading control. Data shown are representative of at least three independent experiments. C Representative luciferase reporter assay from HeLa cells transfected with an AP-1 luciferase reporter, in the presence or absence of JNK-IN-8 $(3 \mu \mathrm{M})$ or SP600125 (10 $\mu \mathrm{M})$. Promoter activity was measured using a dual-luciferase system. Data are presented as relative to the DMSO control. D Luciferase reporter assay from HeLa cells co-transfected with an AP-1 luciferase reporter and pool of siRNA against the JNK substrate c-Jun. Promoter activity was measured using a dual-luciferase system. Data are presented as relative to the scrambled siRNA transfection control. E Representative luciferase reporter assay from HeLa cells co-transfected with an AP-1 luciferase reporter and c-Jun. Promoter activity was measured using a dual-luciferase system. Data are presented as relative to the pcDNA transfection control. Error bars represent the mean $+/-$ standard deviation of a minimum of three biological repeats. $* P<0.05$, $* * P<$ $0.01, * * * P<0.001$ (Student's $t$-test).
Given that HPV E6 induced JNK1/2 phosphorylation, we investigated if E6 was responsible for the observed JNKdependent AP-1 activity. Expression of HPV18 E6 increased c-Jun phosphorylation and enhanced AP-1 activity (Fig. 3C, D). Importantly, the increase in c-Jun phosphorylation and AP-1 activity was abolished in cells treated with inhibitors of JNK1/2.

To gain a greater insight into how HPV E6 increased JNK1/2 phosphorylation, we utilised a number of wellcharacterised E6 mutants. Both HPV18 E6-F4V, which cannot induce p53 degradation [39], and E6-L52A, which inhibits the interaction with E6AP [40], increased JNK1/2 phosphorylation to levels comparable with wild type (WT) E6. In contrast, an E6 mutant lacking the carboxyl-terminal PBM ( $\triangle \mathrm{PDZ}$; [41]) failed to increase JNK1/2 phosphorylation, suggesting that E6 binding to PDZ-domain-containing proteins is required for JNK1/2 phosphorylation (Fig. 3E). This observation was also confirmed with the HPV16 E6 protein (Fig. 3E). Only E6 proteins from high-risk HPV types contain a PBM. In agreement with this, expression of E6 from the $\alpha$-genus low-risk types 11 , or the $\beta$-genus types HPV 8 and HPV38 did not increase JNK1/2 phosphorylation (Fig. 3F). Together, these data demonstrate that high-risk E6 induces JNK1/2 phosphorylation in a PBM-dependent manner. 

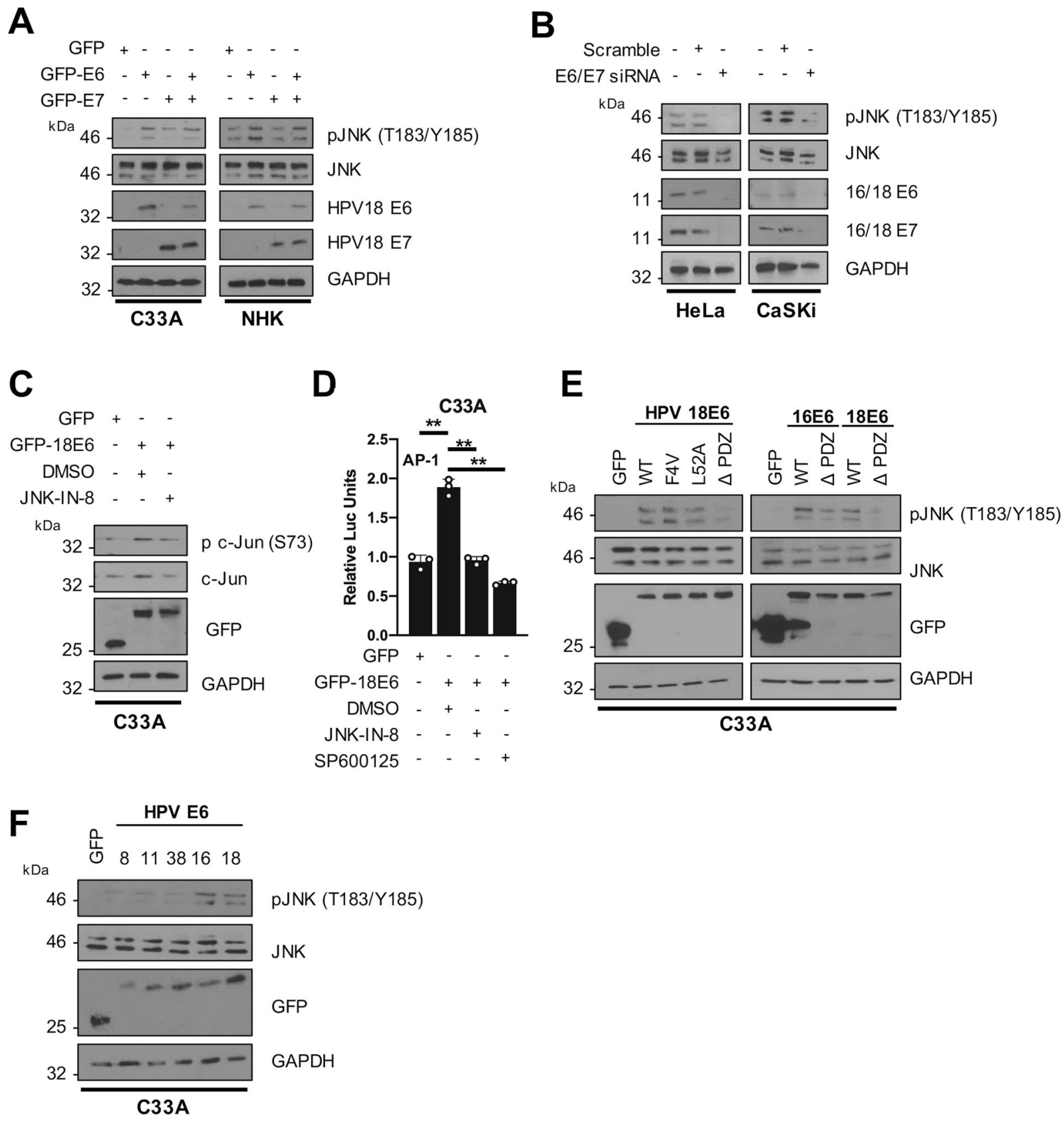

Fig. 3 HPV E6 induces JNK phosphorylation via its PDZ-binding domain. A Representative western blot of C33A and NHK cells transiently transfected with GFP or GFP tagged HPV18 E6, E7 and E6/ E7 and analysed for phosphorylated JNK1/2 and total JNK expression. Expression of HPV oncoproteins was confirmed by fluorescence microscopy for GFP expression (not shown) and HPV18 E6 and HPV18 E7 specific antibodies. GAPDH served as a loading control. Data shown are representative of at least three independent experiments. B Representative western blot of HeLa and CaSKi cells transfected with a pool of specific siRNAs against HPV18 E6/E7 or HPV16 E6/E7 respecitvely and analysed for phosphorylated JNK1/2 and total JNK expression. GAPDH served as a loading control. Data shown are representative of at least three independent experiments. C Representative western blot of C33A cells co-transfected with GFP or GFP tagged E6, in the presence or absence of JNK-IN-8 $(3 \mu \mathrm{M})$. Lysates were analysed for phosphorylated c-Jun and total c-Jun expression. GAPDH served as a loading control. Data shown are representative of at least three independent experiments. D Luciferase reporter assay

from C33A cells co-transfected with GFP or GFP tagged E6, and an AP-1 luciferase reporter, in the presence or absence of JNK-IN-8 (3 $\mu \mathrm{M})$ or SP600125 $(10 \mu \mathrm{M})$. Promoter activity was measured using a dual-luciferase system. Data are presented as relative to the GFP transfection control. E Representative western blot of C33A cells transiently transfected with GFP tagged E6 and E6 mutants and analysed for phosphorylated JNK and total JNK expression. Expression of HPV E6 and mutants was confirmed using a GFP antibody and GAPDH served as a loading control. Data shown are representative of at least three independent experiments. F Representative western blot of C33A cells co-transfected with GFP tagged E6 from different HPV types and analysed for phosphorylated JNK and total JNK expression. Expression of HPV E6 proteins was confirmed using a GFP antibody and GAPDH served as a loading control. Data shown are representative of at least three independent experiments. Error bars represent the mean $+/-$ standard deviation of a minimum of three biological repeats. $* P<0.05, * * P<0.01, * * * P<0.001$ (Student's $t$-test). 


\section{Inhibition of JNK activity is detrimental to HPV+ cervical cancer cell proliferation}

JNK signalling can promote or inhibit cell proliferation, depending on the cellular context $[22,23]$. To assess the impact of JNK/c-Jun activity on cell proliferation, we treated HeLa and CaSKi cells with increasing doses of the JNK1/2 inhibitors JNK-IN-8 and SP600125 [42, 43]. Inhibition of JNK $1 / 2$ resulted in a dose-dependent loss of c-Jun phosphorylation (Fig. 4A and Supplementary Fig. 2A). There was also a reduction in c-Jun expression, as c-Jun positively regulates its own transcription [44]. Inhibition of JNK1/2 led to a significant decrease in cell growth (Fig. 4B) and anchorage-dependent and anchorageindependent colony formation (Fig. 4C, D). Conversely, inhibition of JNK1/2 in HPV- C33A cells had minimal impact on cell growth or colony formation, despite a dosedependent loss of c-Jun phosphorylation and protein expression (Supplementary Fig. 4A-D), suggesting that $\mathrm{HPV}+$ cervical cancer cells are more sensitive to the effects of JNK1/2 inhibition, corresponding with higher levels of JNK1/2 phosphorylation.

Previous studies have demonstrated distinct effects of JNK1 and JNK2 in tumourigenesis [45, 46]. To investigate the contribution of each JNK gene, we utilised dominantnegative JNK1 and JNK2 mutants, in which the phosphorylation motif TPY is mutated to APF, resulting in JNK proteins that cannot be activated or phosphorylate c-Jun (Supplementary Fig. 3A; [47]). We found that both JNK1 and JNK2 are required for cell growth (Supplementary Fig. 3B) and colony formation (Supplementary Fig. 3C-D). These data demonstrate that the activity of both JNK1 and JNK2 is required for the proliferative ability of HPV+ cervical cancer cells.

\section{Active C-Jun/AP-1 is required for the proliferation of HPV + cervical cancer cells}

To confirm whether the JNK-dependent cell proliferation we observed was mediated by c-Jun/AP-1 signalling, we either depleted or over-expressed c-Jun (Fig. 4E and Supplementary Fig. 5A). Depletion of c-Jun significantly reduced cell growth (Fig. 4F) and colony formation (Fig. 4G, H). Conversely, over-expression of c-Jun enhanced cell growth and colony formation (Supplementary Fig. 5B-D), suggesting that c-Jun is required for the proliferation of HPV + cervical cancer cells. In addition, we transfected cells with a dominant-negative JunD $(\Delta \mathrm{JunD})$ lacking a transcriptional activation domain that can dimerize with other AP-1 proteins and inhibit AP-1 activation (Supplementary Fig. 6A; [48]). $\Delta$ JunD expression abolished AP-1 activity in HeLa cells (Supplementary Fig. 6, B), and inhibited cell growth and colony formation
(Supplementary Fig. 6C-E). These data suggest that JNK/cJun/AP-1 signalling is required for the proliferation of $\mathrm{HPV}+$ cervical cancer cells.

\section{Inhibition of JNK/C-Jun induces G2/M phase accumulation and apoptosis in cervical cancer cells}

We investigated if the reduced $\mathrm{HPV}+$ cell proliferation caused by JNK inhibition was caused by modulation of the cell cycle. JNK1/2 inhibition led to a significant increase of cells in the G2/M phase, suggesting that JNK activity was required for progression from $\mathrm{G} 2$ into mitosis, or release from mitosis into G1 (Supplementary Fig. 7A). Depletion of c-Jun led to a similar effect on cell cycle progression (Supplementary Fig. 7D).

Interestingly, inhibition of JNK $1 / 2$ or depletion of c-Jun also resulted in a significant increase in the proportion of cells in sub-G1, which is indicative of apoptosis (Supplementary Fig. 7A and D). We performed Annexin V assays and demonstrated that inhibition of JNK/c-Jun by either approach led to an increase in early and late apoptosis, demonstrating that JNK signalling is required for cell survival in HPV+ cervical cancer cells (Supplementary Fig. 7, $\mathrm{B}$ and E). Mechanistically, we demonstrated that loss of JNK activity or c-Jun expression correlated with the activation of caspase 3, increasing the proteolytic cleavage of PARP (Supplementary Fig. 7C and F). Together, these data suggest that JNK/c-Jun signalling is required for cell cycle progression and survival in HPV + cervical cancer cells.

\section{JNK/C-Jun activity is required for cell migration/ invasion and regulates epithelial to mesenchymal transition (EMT) in cervical cancer cells}

Despite current survival rates demonstrating that existing treatments can be successful in cervical cancer (50-60\% with radiotherapy and concurrent cisplatin treatment), many cases develop local recurrences and metastasise [49]. Furthermore, epithelial-mesenchymal transition (EMT) has been shown to increase cervical cancer progression via increased cell migration and invasion [50]. JNK signalling is a key driver of cell invasion in many cancers $[51,52]$. We therefore investigated if JNK/c-Jun signalling contributed to the invasive phenotype of cervical cancer cells. Inhibition of JNK1/2 or depletion of c-Jun significantly reduced both the migration and invasion of cervical cancer cells through a Transwell ${ }^{\circledR}$ chamber membrane (Fig. 5A-D).

EMT and associated extracellular matrix remodelling are key processes enabling cancer cell invasion. JNK1/2 inhibition or c-Jun depletion reduced expression of matrix metalloprotease (MMP)-9, a crucial enzyme involved in cancer cell invasion (Fig. 5E, F). In addition, the expression of the EMTassociated transcription factors Slug (SNAI2) and ZEB1 
A

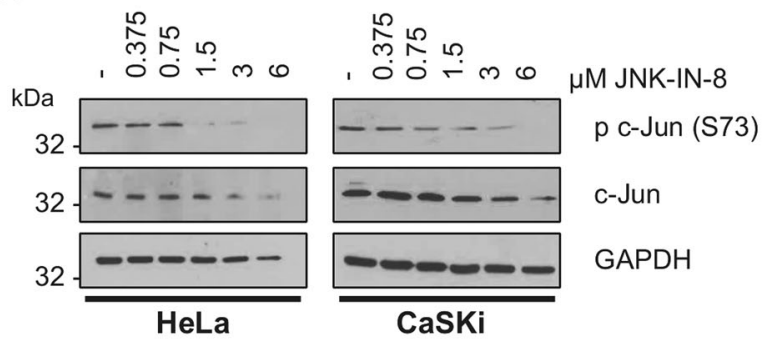

B

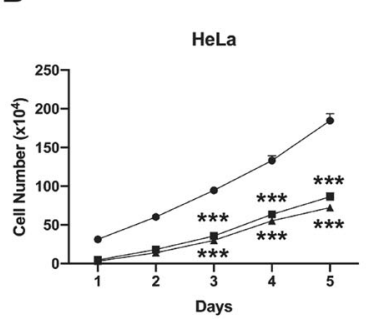

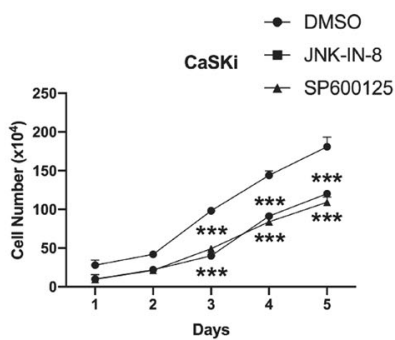

D
C

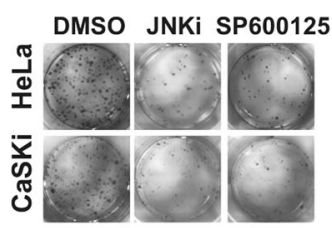

E

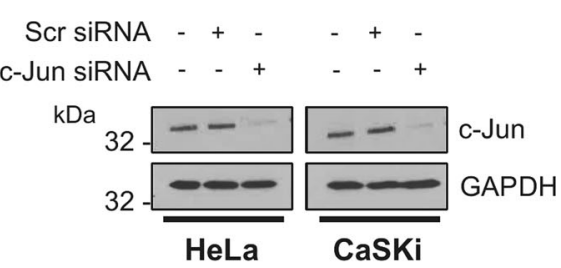

HeLa

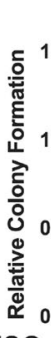

CaSKi

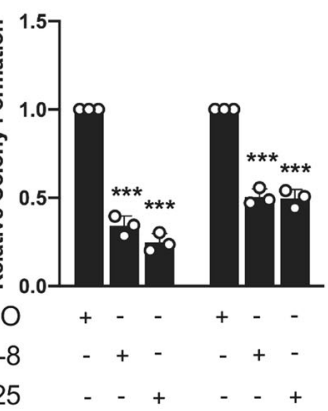

HeLa

CaSKi

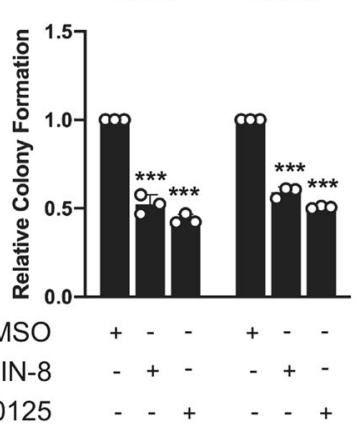

HeLa
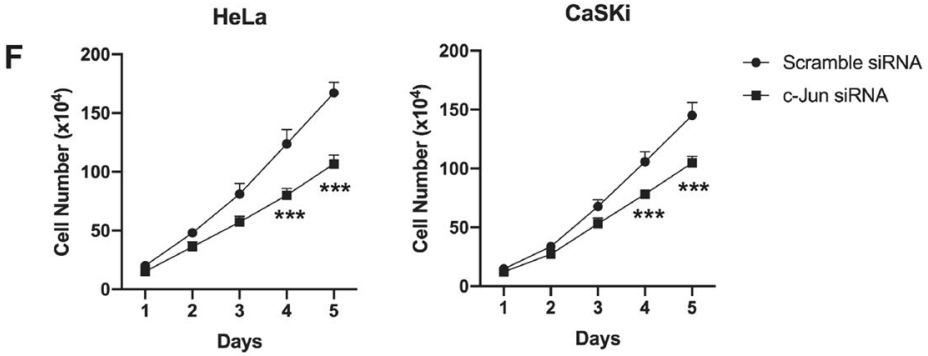

H

G

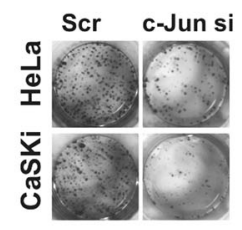

HeLa

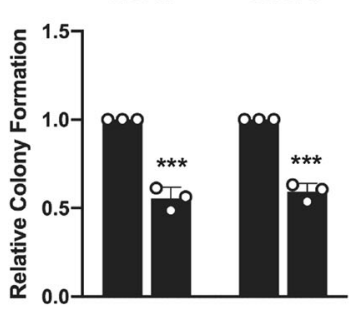

Scr siRNA

c-Jun siRNA
CaSKi

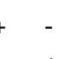

Fig. 4 Inhibition of JNK/c-Jun signalling impaires the proliferation of $\mathrm{HPV}+$ cervical cancer cells. A Representative western blots of HeLa and CaSKi cells treated with increasing doses of JNK-IN-8. Lysates were analysed for the phosphorylation and expression of the JNK substrate c-Jun. GAPDH was used as a loading control. Data shown are representative of at least three independent experiments. B Growth curve analysis of HeLa and CaSKi cells treated with JNKIN-8 $(3 \mu \mathrm{M})$ or SP600125 $(10 \mu \mathrm{M})$. C Colony formation assay (anchorage-dependent growth) of HeLa and CaSKi cells treated with JNK-IN-8 $(3 \mu \mathrm{M})$ or SP600125 $(10 \mu \mathrm{M})$. D Soft agar assay (anchorage-independent growth) of HeLa and CaSKi cells treated with JNKIN-8 $(3 \mu \mathrm{M})$ or SP600125 $(10 \mu \mathrm{M})$. E Representative western blots of

CaSKi

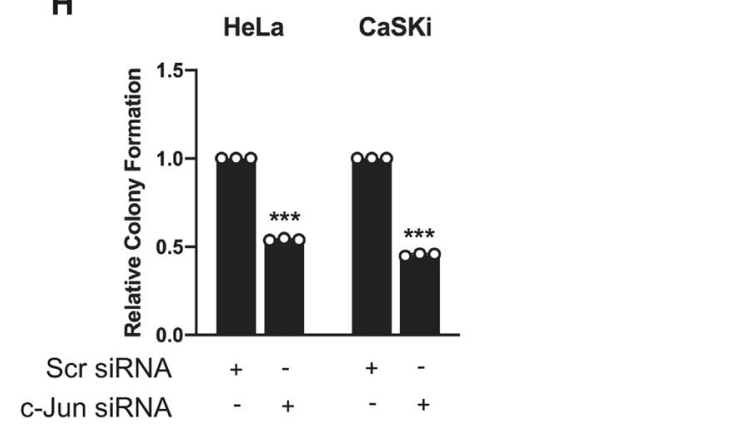

HeLa and CaSKi transfected with a pool of siRNA against c-Jun. Lysates were analysed for the expression of c-Jun. GAPDH was used as a loading control. Data shown are representative of at least three independent experiments. F Growth curve analysis of HeLa and CaSKi cells transfected with a pool of siRNA against c-Jun. G Colony formation assay (anchorage-dependent growth) of HeLa and CaSKi cells transfected with a pool of siRNA against the JNK substrate c-Jun. H Soft agar assay (anchorage-independent growth) of HeLa and CaSKi cells transfected with a pool of siRNA against c-Jun. Error bars represent the mean $+/-$ standard deviation of a minimum of three biological repeats. $* P<0.05, * * P<0.01, * * * P<0.001$ (Student's $t$ test). 
A

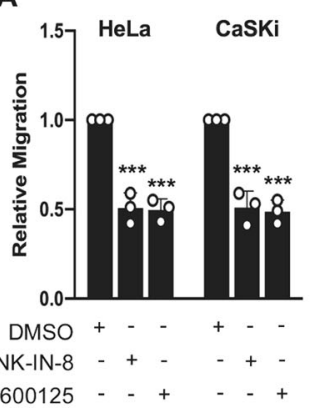

B

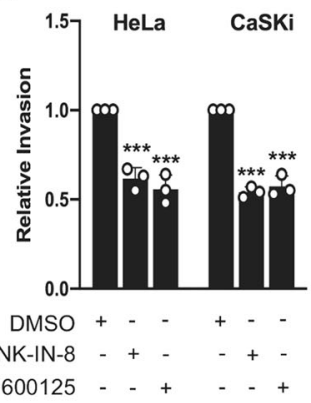

C

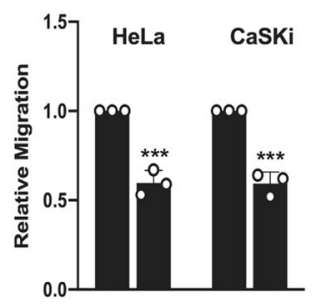

D

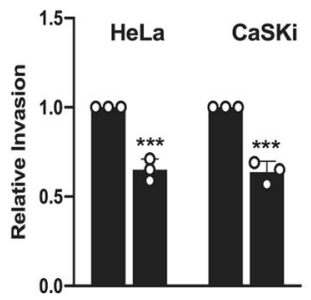

E

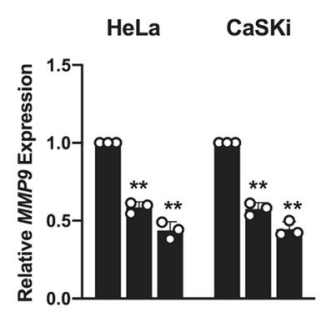

$\mathrm{DMSO}+-$ - + -

JNK-IN-8 - + - - + -

SP600125 - - + - - +

H

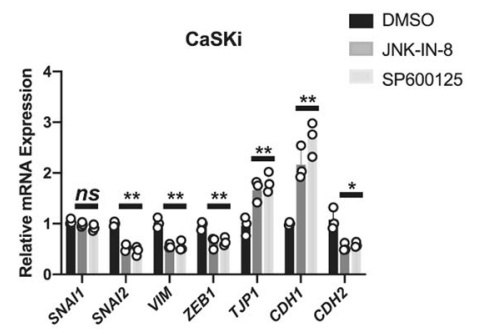

$\mathrm{J}$

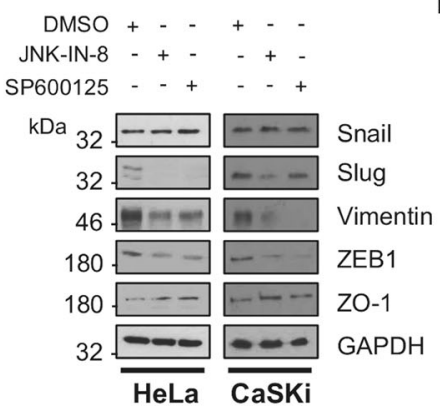

Fig. $5 \mathrm{JNK} / \mathrm{c}$-Jun activity is required for cell migration/invasion and regulates epithelial to mesenchymal transition (EMT). A Transwell ${ }^{\circledR}$ migration assay of HeLa and CaSKi cells treated with JNK-IN-8 $(3 \mu \mathrm{M})$ or SP600125 $(10 \mu \mathrm{M})$. The average number of invaded cells per field was calculated from five representative fields per experiment. B Transwell ${ }^{\oplus}$ invasion assay of HeLa and CaSKi cells treated with JNK-IN-8 $(3 \mu \mathrm{M})$ or SP600125 $(10 \mu \mathrm{M})$. The average number of invaded cells per field was calculated from five representative fields per experiment. C Transwell ${ }^{\circledR}$ migration assay of HeLa and CaSKi cells after transfection of a pool of siRNA against c-Jun. The average number of invaded cells per field was calculated from five representative fields per experiment. D Transwell ${ }^{\oplus}$ invasion assay of HeLa and CaSKi cells after transfection of a pool of siRNA against c-Jun. The average number of invaded cells per field was calculated from five representative fields per experiment. $\mathbf{E}$ qPCR analysis of MMP9 mRNA expression HeLa and CaSKi cells treated with JNK-IN$8(3 \mu \mathrm{M})$ or SP600125 $(10 \mu \mathrm{M})$. U6 was used as a loading control. F qPCR analysis of MMP9 mRNA expression HeLa and CaSKi cells cells after transfection of a pool of siRNA against c-Jun. U6 was used as a

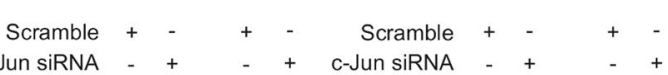

G

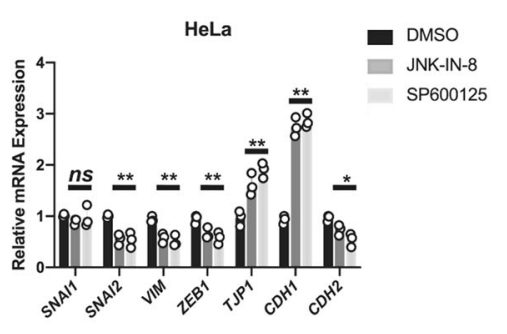

HeLa

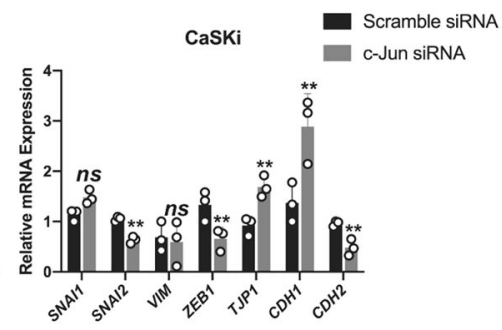

K

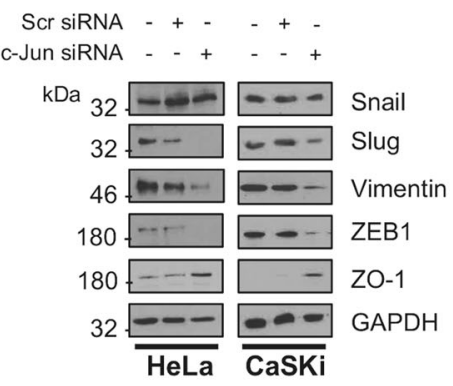

loading control. G qPCR analysis of genes involved in EMT in HeLa cells treated with JNK-IN-8 $(3 \mu \mathrm{M})$ or SP600125 $(10 \mu \mathrm{M})$. U6 was used as a loading control. $\mathbf{H}$ qPCR analysis of genes involved in EMT in CaSKi cells treated with JNK-IN-8 $(3 \mu \mathrm{M})$ or SP600125 $(10 \mu \mathrm{M})$. U6 was used as a loading control. I qPCR analysis of genes involved in EMT in HeLa and CaSKi cells after transfection of a pool of siRNA against c-Jun. U6 was used as a loading control. J Representative western blots of HeLa and CaSKi treated JNK-IN-8 $(3 \mu \mathrm{M})$ or SP600125 $(10 \mu \mathrm{M})$. Lysates were probed for the expression of Slug, Snail, Vimentin, ZO-1 and ZEB1. GAPDH was used as a loading control. Data shown are representative of at least three independent experiments. K Representative western blots of HeLa and CaSKi after transfection of a pool of siRNA against c-Jun. Lysates were probed for the expression of Slug, Snail, Vimentin, ZO-1 and ZEB1. GAPDH was used as a loading control. Data shown are representative of at least three independent experiments. Error bars represent the mean $+/-$ standard deviation of a minimum of three biological repeats. $* P<0.05,{ }^{* *} P<0.01, * * * P<0.001$ (Student's $t$-test). 
(ZEB1), but not Snail (SNAI1), and the mesenchymal markers $\mathrm{N}$-cadherin $(\mathrm{CDH} 2)$ and vimentin $(V I M)$, was also reduced (Fig. 5G-K). Conversely, expression of the epithelial markers E-cadherin $(C D H 1)$ and ZO-1 (TJPl) was increased, suggesting that $\mathrm{JNK} / \mathrm{c}$-Jun activity is required for the invasive potential of cervical cancer cells, potentially through the regulation of EMT-associated proteins.

\section{JNK activity promotes EGFR signalling to regulate proliferation}

In keratinocytes, proliferation is often mediated via binding of the epidermal growth factor (EGF)-family of ligands to the EGF receptor (EGFR) [32, 53, 54]. Several EGF-family ligands, as well as the EGFR itself, are regulated by c-Jun [55-57]. As EGFR signalling can be regulated by HPV E6 [58], we investigated whether the EGFR was required for the enhanced JNK activity observed. For this, HeLa cells were serum starved and treated with EGF (Supplementary Fig. 8). EGF treatment caused rapid and transient EGFR autophosphorylation (Y1068) and rapidly induced JNK1/2 phosphorylation, which peaked 10 min post-treatment and was undetectable $30 \mathrm{~min}$ post-treatment. This was followed by phosphorylation of the JNK substrates c-Jun and JunD, which started $15 \mathrm{~min}$ post treatment and peaked $45 \mathrm{~min}$ post treatment. By $1 \mathrm{~h}$, an increase in both c-Jun and JunD protein expression was observed. These data show that EGF activated the JNK/c-Jun signalling pathway in cervical cancer cells.

We next investigated if the JNK/c-Jun pathway regulated EGFR signalling in cervical cancer cells. First, we inhibited JNK activity and used qRT-PCR to measure the expression of EGFR and the EGFR ligands EGF, transforming growth factor $\alpha(\mathrm{TGF} \alpha)$ and heparin-binding EGF (HB-EGF). Inhibition of JNK activity significantly reduced EGFR, $E G F$ and $H B E G F$ expression, without affecting the expression of TGFA (Fig. 6A). This led to a loss of EGFR protein expression (Fig. 6B). Knockdown of c-Jun had similar effects (Fig. 6C, D), suggesting that JNK/c-Jun signalling regulated the expression of key EGFR signalling components in cervical cancer cells. Data from the TCGA demonstrated that c-Jun expression correlated with EGFR, $E G F$ and $H B E G F$ expression (Fig. 6E).

Next, we assessed if impaired EGFR signalling was responsible for the reduction in proliferation observed upon inhibition of the JNK/c-Jun pathway. To do this, we incubated cells previously treated with DMSO or SP600125 (as SP600125 is a reversible inhibitior [42]) in conditioned media from cells treated with DMSO or SP600125 (diagram in Fig. 6F). Incubation of DMSO treated cells with conditioned media taken from SP600125-treated cells significantly reduced colony formation (Fig. 6G, compare bar 2 to bar 1). To determine if this was due to impaired EGF/
HB-EGF-EGFR signalling, we supplemented conditioned media from SP600125 cells with EGF or HB-EGF. The addition of either EGFR ligand restored colony formation to control levels (Fig. 6G, compare bars 3 and 4 with bar 1). We confirmed that the restoration of colony formation was due to EGFR signalling, as co-incubation of EGF or HBEGF with a neutralising EGFR antibody nullified this effect (compare bars 3 and 4 with bars 5 and 6).

To confirm these findings, we incubated SP600125treated cells, which exhibit reduced colony formation (Fig. 4C), with conditioned media from DMSO treated cells, which should contain normal levels of EGF and HBEGF. In agreement with our previous data, this restored colony formation to control levels (Fig. 6G, compare bar 7 with bar 1). This supports the hypothesis that a soluble factor may rescue proliferation in cells in which JNK1/2 was inhibited. The addition of media containing a neutralising EGFR antibody failed to rescue colony formation, suggesting that EGFR signalling plays a role in the diminished proliferative ability of JNK-inhibited cervical cancer cells (Fig. 6G, compare bar 8 with bar 7). Finally, to confirm if EGF and/or HB-EGF were the EGFR ligands implicated in the restoration of proliferation, we incubated conditioned media from DMSO treated cells with neutralising antibodies against EGF and/or HB-EGF. The addition of media containing either or both neutralising antibodies failed to rescue colony formation (Fig. 6G, compare bars 9, 10 and 11 with bar 7). Taken together, these data suggest that EGF/HB-EGF-EGFR signalling is required for the proliferative ability of $\mathrm{HPV}+$ cervical cancer cells, and this signalling axis is reduced in cells in which JNK is inhibited.

\section{JNK mediated c-Jun activation plays a critical role in HPV oncogene expression}

The continued expression of the viral oncogenes E6 and E7 is required for the proliferation and survival of HPVassociated cancers [59]. Viral oncogene expression is regulated by host transcription factors through binding to the upstream regulatory region (URR) in the virus genome [60]. The URR contains AP-1 binding sites in both the promoter and enhancer regions that can bind c-Jun and induce E6/E7 expression [61-65]. The signalling that governs this AP-1 dependent induction of E6/E7 is unclear. To investigate if JNK signalling played a role, we assessed the activity of the viral URR using a reporter construct containing the HPV18 URR sequence [65]. Inhibition of JNK1/ 2 led to a $\sim 90 \%$ reduction in URR-driven luciferase levels, suggesting that JNK signalling is critical for viral transcription (Fig. 7A). In addition, treatment of HeLa and CaSKi cells with JNK inhibitors resulted in a significant reduction in E6/E7 mRNA expression (Fig. 7B). Depletion 
A

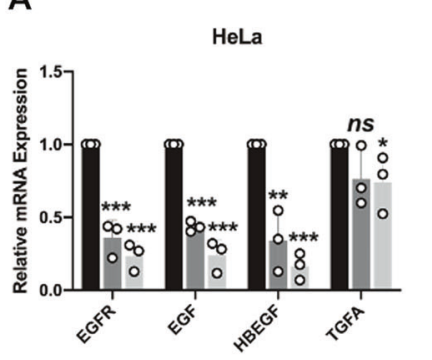

C

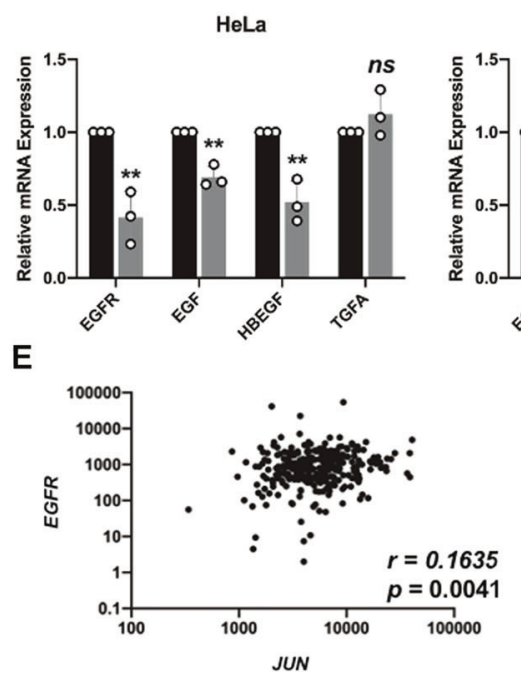

DMSO

JNK-IN-8 SP600125

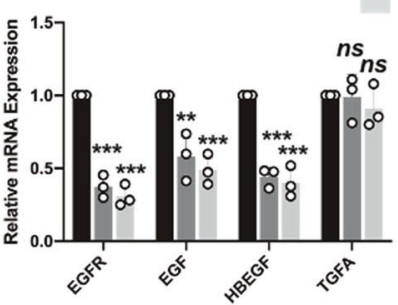

Caski

Scramble siRNA C-Jun SiRNA
B

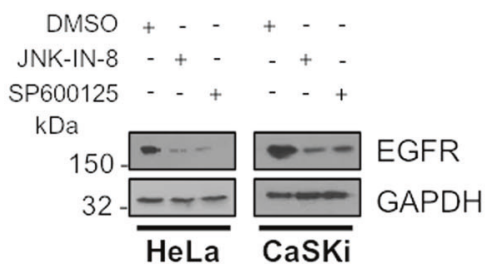

D
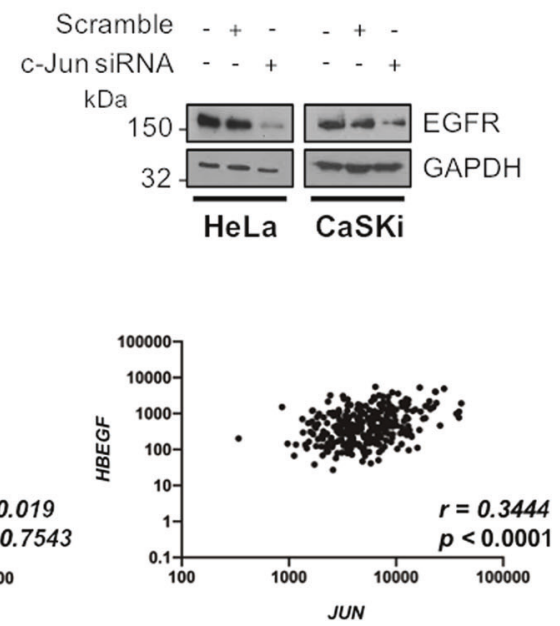

$\mathbf{F}$

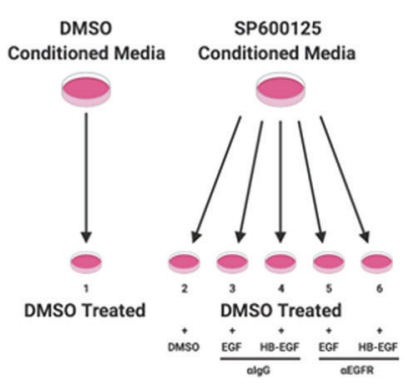

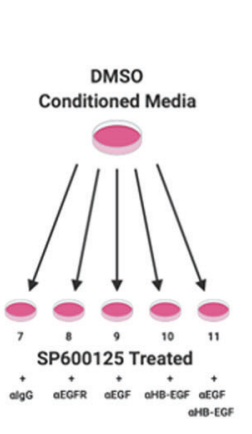

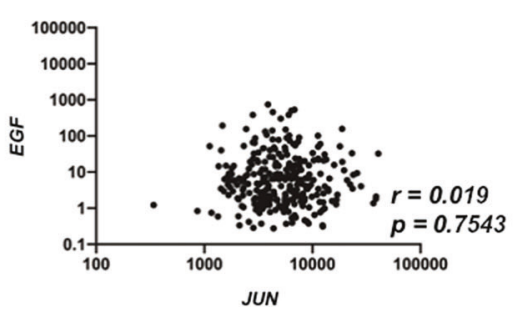

G

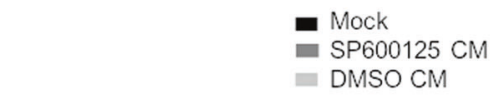

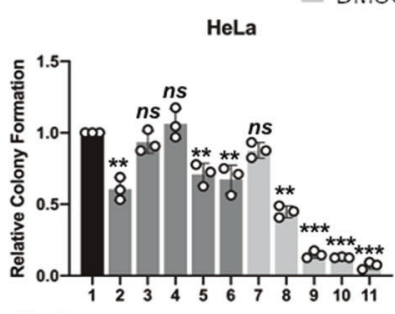

Mock + - . . - . - -

DMSO CM - - - - - + + + + +

SP600125 CM - + + + + + - - -

EGF - - + + - - - -

HB-EGF - - - + - + - - - -

$\alpha \lg \mathrm{C}-\ldots+\ldots+\ldots$

$\alpha$ EGFR - - - + + + + - -

$\alpha \mathrm{EGF}$ - - - - - - + +

aHB-EGF _ . . . . . . + +

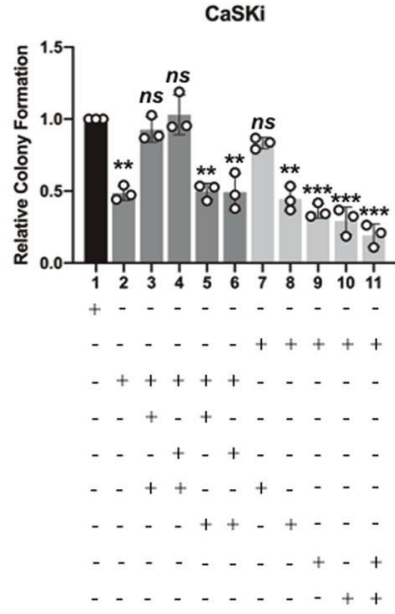

Fig. 6 Regulation of EGFR signalling contributes to JNK mediated proliferation. A qPCR analysis of EGFR and EGFR ligand expression in HeLa and CaSKi cells treated with JNK-IN-8 $(3 \mu \mathrm{M})$ or SP600125 (10 $\mu \mathrm{M})$ for $48 \mathrm{~h}$. U6 was used as a loading control. B) Representative western blots of HeLa and CaSKi cells treated with JNK-IN-8 $(3 \mu \mathrm{M})$ or SP600125 $(10 \mu \mathrm{M})$ for the expression of EGFR for $48 \mathrm{~h}$. Data shown are representative of at least three independent experiments. C qPCR analysis of EGFR and EGFR ligand expression in HeLa and CaSKi cells after transfection of a pool of siRNA against c-Jun for $72 \mathrm{~h}$. U6 was used as a loading control. D Representative western blot of HeLa and CaSKi cells after transfection of a pool of siRNA against c-Jun for the expression of EGFR for $72 \mathrm{~h}$. Data shown are representative of at least three independent experiments. E Scatter plot of expression levels of $J U N$ and $E G F R$,
$E G F$ and $H B E G F$ as analysed using the MD Anderson public RPPA data set. The correlation coefficient $(r)$ was calculated using Spearman's rank analysis. F Schematic for conditioned media rescue assay. G Colony formation assay (anchorage-dependent growth) of $\mathrm{HeLa}$ and $\mathrm{CaSKi}$ treated with SP600125 $(10 \mu \mathrm{M})$ or DMSO control for $48 \mathrm{~h}$. SP600125 was subsequently washed out and control or SP600125-treated cells were grown in conditioned media from cells treated with DMSO or SP600125. In addition, cells were also grown in SP600125 conditioned media containing EGF, HB-EGF, or DMSO conditioned media with or without neutralising EGFR, EGF or HB-EGF antibodies. Colonies were stained and counted after 14 days. Error bars represent the mean $+/$ - standard deviation of a minimum of three biological repeats. $* P<0.05$, $* * P<$ $0.01, * * * P<0.001$ (Student's $t$-test). 
of the JNK substrate c-Jun also reduced E6/E7 mRNA (Fig. 7C) and protein (Fig. 7D, E) expression.

ChIP analysis was used to confirm if JNK1/2 inhibition resulted in reduced c-Jun recruitment to the viral URR, utilising primers covering the AP-1 binding sites in both the viral promoter and enhancer. JNK inhibition led to a significant reduction in c-Jun recruitment to the AP-1 binding sites in both the viral promoter and enhancer (Fig. 7F).

As we had demonstrated a role for EGF signalling in JNK activity, we assessed if JNK was responsible for EGFinduced E6/E7 expression. Treatment of HeLa cells with

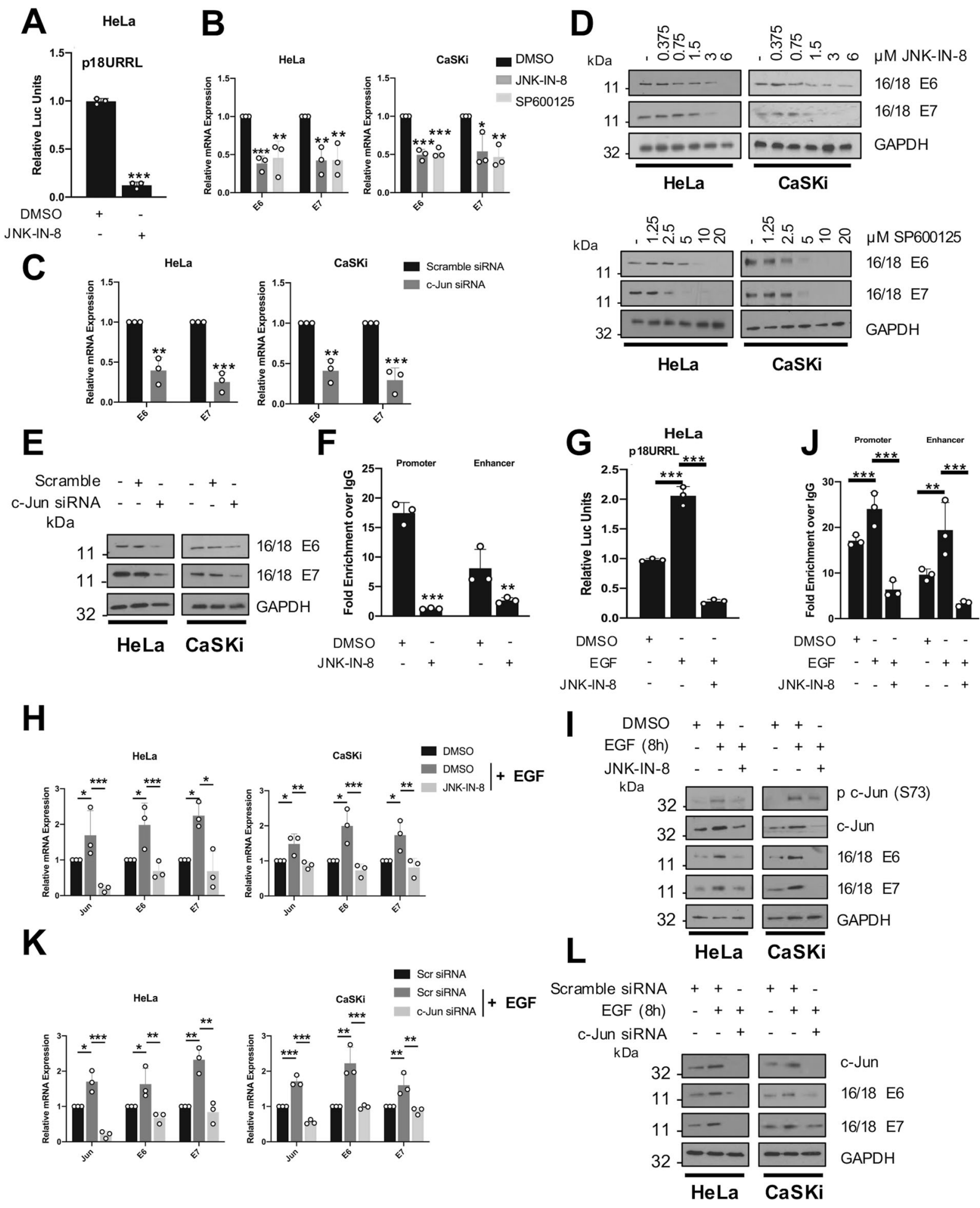


Fig. 7 JNK mediated c-Jun activation plays a significant role in HPV oncogene expression. A Luciferase reporter assay from HeLa cells transfected with a HPV18 URR luciferase reporter with or without treatment with JNK-IN-8 $(3 \mu \mathrm{M})$. Promoter activity was measured using a dual-luciferase system. Data are presented as relative to the DMSO control. B qPCR analysis of HPV 16/18 E6 and E7 mRNA expression in HeLa and CaSKi cells treated with JNK-IN-8 (3 $\mu \mathrm{M})$. U6 was used as a loading control. C qPCR analysis of HPV 16/ 18 E6 and E7 mRNA expression in HeLa and CaSKi cells after transfection of a pool of siRNA against c-Jun. U6 was used as a loading control. D Representative western blots of HeLa and CaSKi treated with increasing doses of JNK-IN-8 $(3 \mu \mathrm{M})$ or SP600125 (10 $\mu \mathrm{M})$. Lysates were analysed for the expression of HPV 16/18 E6 and E7. GAPDH was used as a loading control. Data shown are representative of at least three independent experiments. E Representative western blots of HeLa and CaSKi after transfection of a pool of siRNA against c-Jun. Lysates were analysed for the expression of HPV 16/18 E6 and E7. GAPDH was used as a loading control. Data shown are representative of at least three independent experiments. F ChIP-qPCR analysis of c-Jun binding to the HPV18 URR in HeLa cells with or without JNK-IN-8 $(3 \mu \mathrm{M})$. Chromatin was prepared from HeLa cells and c-Jun was immunoprecipitated using an anti-c-Jun antibody, followed by RT-qPCR using primers specific to AP-1 binding sites in the HPV18 URR enhancer or promoter region. c-Jun binding is presented as percentage of input chromatin. G Luciferase reporter assay from HeLa cells transfected with a HPV18 URR luciferase reporter and treated with EGF $(50 \mathrm{ng} / \mathrm{mL}, 8 \mathrm{~h})$ with or without treatment with JNKIN-8 $(3 \mu \mathrm{M})$. Promoter activity was measured using a dual-luciferase system. Data are presented as relative to the GFP transfected control. $\mathbf{H}$ qPCR analysis of HPV 16/18 E6 and E7 mRNA expression in HeLa and CaSKi cells treated with EGF $(50 \mathrm{ng} / \mathrm{mL}, 8 \mathrm{~h}$ ) with or without JNK-IN-8 $(3 \mu \mathrm{M})$. U6 was used as a loading control. I Representative western blots of HeLa and CaSKi treated with EGF $(50 \mathrm{ng} / \mathrm{mL}, 8 \mathrm{~h})$ with or without JNK-IN-8 $(3 \mu \mathrm{M})$. Lysates were analysed for the expression of HPV 16/18 E6 and E7. GAPDH was used as a loading control. Data shown are representative of at least three independent experiments. J ChIP-qPCR analysis of c-Jun binding to the HPV18 URR in HeLa cells treated with EGF $(50 \mathrm{ng} / \mathrm{mL}, 8 \mathrm{~h}$ ), with or without JNK-IN-8 $(3 \mu \mathrm{M})$. Chromatin was prepared from HeLa cells and c-Jun was immunoprecipitated using an anti-c-Jun antibody, followed by RT-qPCR using primers specific to AP-1 binding sites in the HPV18 URR enhancer or promoter region. c-Jun binding is presented as percentage of input chromatin. K qPCR analysis of HPV 16/18 E6 and E7 mRNA expression in HeLa and CaSKi cells treated with EGF (50 $\mathrm{ng} / \mathrm{mL}, 8 \mathrm{~h}$ ) after transfection of a pool of siRNA against c-Jun. U6 was used as a loading control. L Representative western blots of HeLa and CaSKi treated with EGF $(50 \mathrm{ng} / \mathrm{mL}, 8 \mathrm{~h})$ after transfection of a pool of siRNA against c-Jun. Lysates were analysed for the expression of HPV E6 and E7. GAPDH was used as a loading control. Data shown are representative of at least three independent experiments. Error bars represent the mean $+/-$ standard deviation of a minimum of three biological repeats. $* P<0.05, * * P<0.01, * * * P<0.001$ (Student's $t$-test).

EGF increased viral transcription and E6/E7 expression (Fig. 7G-I); critically, inhibition of JNK abolished this EGF-induced oncoprotein expression. Further, EGF stimulation increased binding of c-Jun to the viral URR in a JNKdependent manner (Fig. 7J). As expected, depletion of c-Jun also led to a reduction in EGF-induced viral transcription and E6/E7 expression, demonstrating that c-Jun is required for the EGF-induced E6/E7 expression (Fig. 7K, L).

\section{Discussion}

Despite the availability of preventative vaccines against HPV, there is a lack of specific therapies targetting HPVassociated malignancies. As such, there is a critical need for research into the fundamental biology of the virus-host interactions to identify host factors that are essential in HPV-associated cancers. Indeed, targetting host cell proteins with small molecule inhibitors or nucleic acid mimics has shown potential as antiviral therapies for a number of oncogenic viruses, including Kaposi's sarcoma-associated herpesvirus (KSHV; [66]) and HPV [14, 67]. HPV manipulates signalling pathways which contribute to its oncogenic potential, including the JAK/STAT [13, 14, 29], PI3K/AKT [10, 68], Hippo [69] and MAPK pathways $[17,19]$. Here, we show aberrant JNK signalling in HPVcontaining keratinocytes and cervical cancer cells.

JNK activity can be either tumour suppressive or oncogenic, depending on the cellular context. For instance, JNK activity is associated with the induction of apoptosis and can suppress Ras-induced transformation in MEF xenografts [23]. In contrast, JNK is essential for transformation by oncogenic Ras in lung carcinoma and c-Met in mouse fibroblasts [22, 70]. Many of these pro-oncogenic functions of JNK are dependent on the c-Jun transcription factor $[25,32]$. Thus, the function of JNK activity is cancer and cell-type specific. Using a combination of samples from patients with cervical disease and cervical cancer tissue, we show that JNK1/2 phosphorylation correlates with cervical disease progression and is increased in cervical cancer tissue and in HPV + cervical cancer cell lines. This corresponds with previous data demonstrating high levels of JNK1/2 phosphorylation in cervical cancer [71]. Our data demonstrate that the increased JNK1/2 phosphorylation correlates with enhanced c-Jun phosphorylation and AP-1 activity, which is a key regulator of proliferation in many malignancies, including cervical cancer [72-74]. Importantly, we demonstrate that inhibition of JNK1/2 using small molecule inhibitors, inactive mutants and depletion of the JNK substrate c-Jun reduces cell proliferation and increases apoptosis.

We also observed that the inhibition of JNK $1 / 2$ in $\mathrm{HPV}+$ cervical cancer cells increased the proportion of cells in the G2 phase of the cell cycle, consistent with previous reports [75]. This can lead to endoreduplication, mitotic spindle deformation and delayed apoptosis [76, 77]. The increase in sub-G1 DNA observed upon JNK1/2 inhibition in this study suggests that the mechanism of apoptosis observed in cervical cancer cells may be due to mitotic defects.

In addition, we demonstrate that the reduced proliferative capacity of HPV + cells observed upon JNK1/2 inhibition is at least partially due to a defect in EGFR signalling, 
which has previously been shown in skin tumours in which the $J U N$ gene has been deleted [32, 53, 78, 79]. Here, disrupted JNK signalling reduced expression of $E G F$, $H B E G F$ and EGFR. Experiments using conditioned media from control or JNK1/2 inhibitor-treated cells demonstrated that the proliferative defect upon JNK1/2 inhibition was rescued by the addition of soluble factors that were blocked by a neutralising EGFR antibody, suggesting they function through the EGFR. In confirmation of this, the addition of EGF or HB-EGF to conditioned media from JNK1/2inhibited cells also rescued the proliferation defect. Neutralising antibodies against EGF or HB-EGF not only inhibited the restoration of proliferation, but inhibited proliferation to a greater extend that the SP600125-treated conditioned media. This suggests that these ligands may also signal via receptors other than the EGFR. EGF has been shown to activate ErbB4 homodimers, and both EGF and HB-EGF can activate HER2/ErbB4 heterodimer mediated mitogenic signalling [80]. Thus, the enhanced proliferation defect observed upon addition of EGF and/or HB-EGF neutralising antibodies may be due to the inhibition of mitogenic signalling through other ErbB receptors, not just the EGFR. Together, our data indicate that impaired EGFR/ErbB signalling contributes, in part, to the proliferative defects observed in HPV+ cervical cancer cells upon inhibition of JNK signalling.

HPV E6 has previously been shown to induce JNK/c-Jun phosphorylation in lung cancer cells [81]; however, a clear role for E6-mediated JNK/c-Jun signalling in cervical cancer cells is lacking. Our data demonstrate that the HPV E6 oncogene is responsible for JNK1/2 phosphorylation. We further demonstrate that this is dependent on the PBM found only in high-risk E6 proteins. As such, the induction of JNK1/2 phosphorylation may be an oncogenic function of E6. It is not clear how binding to cellular PDZ domains modulates JNK1/2 phosphorylation. Several PDZ-domain-

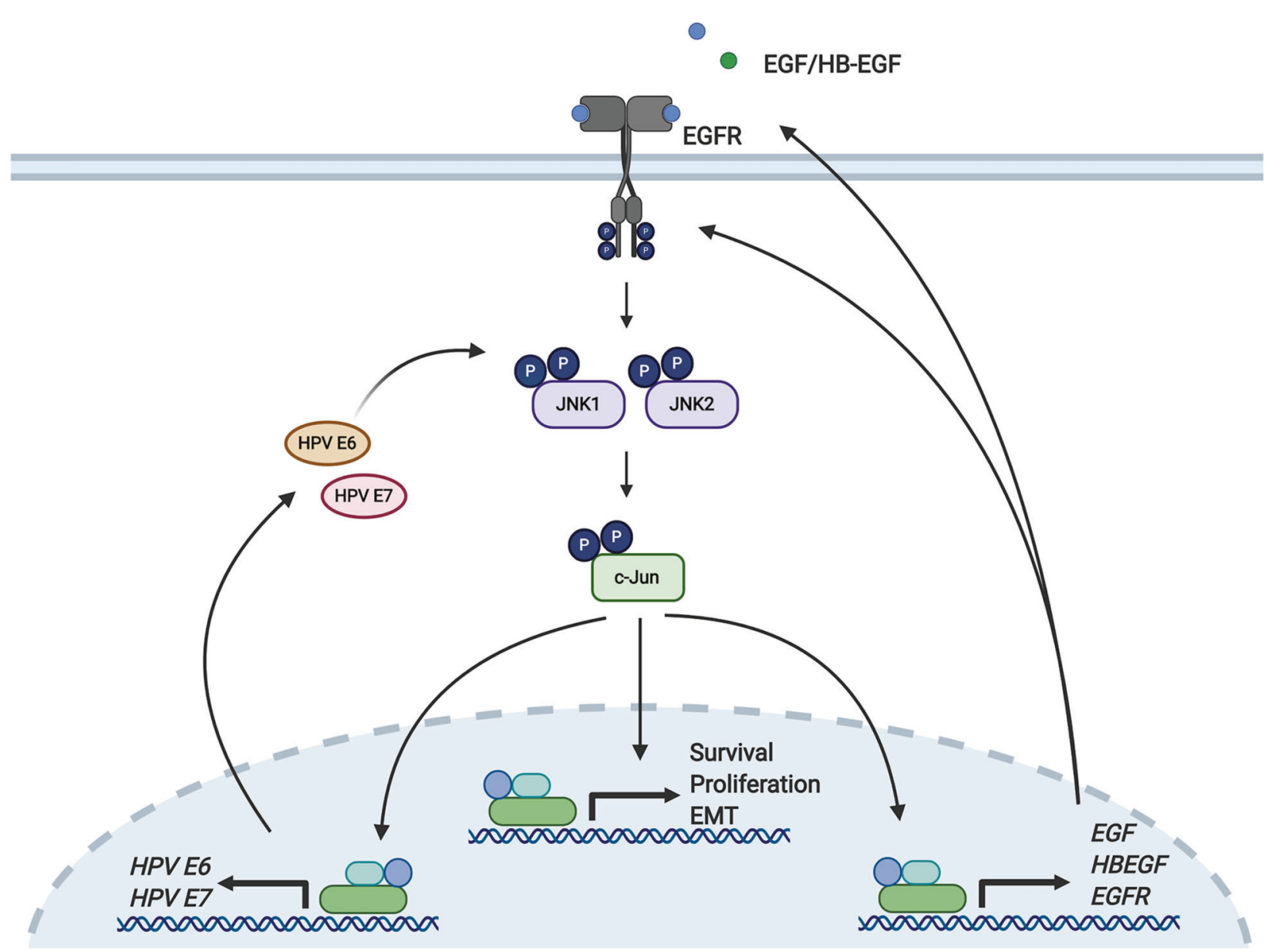

Fig. 8 Schematic demonstrating E6-mediated JNK activation and downstream signalling. HPV E6 induces JNK1/2 phosphorylation and subsequent c-Jun/AP-1 activation. This drives the activation of genes involved in cell proliferation, such as EGFR and EGF ligands, which subsequently forms a positive feedback loop, driving JNK activation and proliferation. JNK signalling also drives the expression of genes involved in cell migration, invasion and EMT. Furthermore, the JNK/c-Jun/AP-1 signalling axis is required for basal and EGFinduced viral oncogene expression. Figure was created using BioRender.com. 
containing targets of E6 are involved in cell polarity [82]; in combination with oncogenic Ras mutants, loss of the cell polarity proteins, and known E6 targets, Scribble and DLG1, require JNK1/2 activation for tumourigenesis [83]. In addition, a Drosophila model of E6-mediated malignancy demonstrated a key role for the polarity protein MAGI [84]. Thus, HPV E6-mediated degradation of cell polarity proteins may be required to induce JNK1/2 phosphorylation.

Constitutive expression of the viral oncogenes E6 and E7 is essential for cancer progression. However, our understanding of the regulation of viral oncogene expression by host cell factors is incomplete. Previous data have demonstrated that the viral URR contains transcription factor binding sites necessary for viral oncogene expression $[60,85]$. Interestingly, two AP-1 binding sites have been identified in the HPV18 URR, one in the enhancer region and one in the promoter, which are important in viral transcription [65]. Here, we demonstrate that the JNK signalling pathway is critical for the expression of HPV E6/E7. Importantly, the JNK substrate c-Jun mediates the effect of JNK activity on viral transcription, as recruitment of c-Jun to the AP-1 binding sites in the URR is abolished upon JNK1/2 inhibition. Furthermore, E6/E7 expression has previously been demonstrated to be induced by EGFR signalling [86, 87]; our data demonstrate that this requires JNK activity.

Our study has uncovered the presence of a complex positive feedback loop in HPV + cervical cancer cells (Fig. 8). In this pathway, HPV E6 activates JNK, which then phosphorylates and activates c-Jun, which transactivates host genes regulating cell growth and survival and can also bind AP-1 sequences in the HPV URR to drive expression of HPV E6/E7. Upregulated host factors include both the EGFR and its ligands EGF and HB-EGF. Signalling driven from the EGFR in turn activates JNK to potentiate the pathway. The existence of this signalling loop offers a potential target for therapy in HPV-associated cancers.

\section{Materials and methods}

\section{Cervical cytology samples}

Cervical cytology samples were obtained from the Scottish HPV Archive (http://www.shine/mvm.ed.ac.uk/archive. shtml). The East of Scotland Research Ethics Service has given generic approval to the Scottish HPV Archive as a Research Tissue Bank (REC Ref 11/AL/0174) for HPV related research on anonymised archive samples. Samples are available for the through application to the Archive Steering Committee (HPV Archive Application Ref 0034).
RNA and protein were extracted from the samples using Trizol $^{\mathrm{TM}}$ as described by the manufacturer (ThermoFisher Scientific, USA).

\section{TMA and immunohistochemistry}

A cervical cancer TMA containing 39 cases of cervical cancer and 9 cases of normal cervical tissue (in duplicate) were purchased from GeneTex, Inc. (GTX21468). Slides were deparaffinised in xylene, rehydrated in a graded series of ethanol solutions and subjected to antigen retrieval in citric acid. Slides were blocked in normal serum and incubated in primary antibody (Phospho-SAPK/JNK (Thr183/ Tyr185) (81E11; 4668, Cell Signalling Technology (CST))) overnight at $4{ }^{\circ} \mathrm{C}$. Slides were then processed using the VECTASTAIN $^{\circledR}$ Universal Quick HRP Kit (PK-7800; Vector Laboratories) as per the manufacturer's instructions. Immunostaining was visualised using 3,3'-diaminobenzidine (Vector ${ }^{\circledast}$ DAB (SK-4100; Vector Laboratories)). Phospho-JNK immunostaining quantification was automated using ImageJ with the IHC Profiler plug-in [88]. Histology scores (H-score) were calculated based on the percentage of positively stained tumour cells and the staining intensity grade [89]. The staining intensities were classified into the following four categories: 0, no staining; 1, low positive staining; 2 , positive staining; 3 , strong positive staining. $\mathrm{H}$ score was calculated by the following formula: $(3 \times$ percentage of strong positive tissue $)+(2 \times$ percentage of positive tissue) + (percentage of low positive tissue), giving a range of $0-300$.

\section{Cell culture}

HeLa (HPV18+ cervical epithelial adenocarcinoma cells), SW756 (HPV18+ cervical squamous carcinoma cells), $\mathrm{SiHa}$ (HPV16+ cervical squamous carcinoma cells), CaSKi (HPV16+ cervical squamous carcinoma cells), C33A (HPV - cervical squamous carcinoma) and DoTc2-4510 (HPV-cervical squamous carcinoma) cells obtained from the ATCC were grown in DMEM supplemented with $10 \%$ Foetal Bovine Serum (FBS; ThermoFisher Scientific, USA) and $50 \mathrm{U} / \mathrm{mL}$ penicillin (Lonza, USA). Primary NHKs isolation from neonate foreskin tissues (ethical approval no. 06/Q1702/45) was performed in S. Roberts' laboratory as described previously [90] and were maintained in serumfree medium (SFM; GIBCO, UK) supplemented with $25 \mu \mathrm{g}$ / $\mathrm{mL}$ bovine pituitary extract (GIBCO) and $0.2 \mathrm{ng} / \mathrm{mL}$ recombinant EGF (GIBCO). All cells were cultured at $37^{\circ}$ $\mathrm{C}$ and $5 \% \mathrm{CO}_{2}$. The generation HPV18 containing NHKs has been previously described [5].

All cells were negative for Mycoplasma during this investigation. Cell identity was recently confirmed by STR profiling. 


\section{Plasmids, siRNA and reagents}

Plasmids for HPV oncoproteins have been previously described [29]. pAP1-luc, a luciferase reporter construct regulated by a promoter sequence responsive to AP-1, has been previously described [91]. p18URRL, a luciferase reporter construct regulated by the HPV18 viral URR, has been previously described [65] and was kindly provided by Prof. Felix Hoppe-Seyler (German Cancer Research Center, Heidelberg, Germany). pcDNA3 FLAG JNK1a1 (APF) and JNK2a2 (APF) mutants were obtained from Addgene (\#13846 and \#13761). c-Jun and $\Delta \mathrm{JunD}$ were kindly provided by Prof. Simon Arthur (University of Dundee). HPV16 E6 siRNA was purchased from Santa Cruz Biotechnology (SCBT) and had the following sequence: $5^{\prime}$ UGUGUACUGCAAGCAACAG- ${ }^{\prime}$. The HPV18 E6 siRNAs were purchased from Dharmacon (GE Healthcare) and had the following sequences: $5^{\prime}$-CUAACACUGGGUUA UACAA- ${ }^{\prime}$ and $5^{\prime}$-CTAACTAACACTGGGTTAT- ${ }^{\prime}$. The HPV16 and HPV18 E7 siRNA were as previously described and were a kind gift from Prof. Eric Blair (University of Leeds) [92, 93]. siRNA targetting c-Jun were purchased from Qiagen (FlexiTube GeneSolution GS3725 for JUN; SI03077599, SI00034678, SI00034671, SI00034664). The small molecule inhibitors JNK-IN-8 (covalent, irreversible JNK inhibitor), SP600125 (reversable JNK inhibitor), U0126 (MEK1/2 inhibitor) and SB203580 (p38 inhibitor) were purchased from Calbiochem. Human recombinant EGF (236-EG) and HB-EGF (259-HE) were purchased from R\&D Systems. Human anti-EGF (MAB236-SP), human anti-HB-EGF (AF-259-SP) and anti-mouse IgG1 control (MAB002) antibodies were purchased from R\&D Systems.

\section{Transfections and mammalian cell lysis}

Transfection of plasmid DNA was performed with a DNA to Lipofectamine ${ }^{\circledR} 2000$ (ThermoFisher) ratio of 1:2.5. $48 \mathrm{hr}$ post transfection, cells were lysed in lysis buffer for western blot analysis, or reseeded into new plates for growth curve analysis, colony formation assays or soft agar assays. Transfection of siRNA was performed with a siRNA to Lipofectamine $^{\circledast} 2000$ ratio of 1:2. 72-h post transfection cells were lysed in lysis buffer for western blot analysis, or reseeded into new plates for growth curve analysis, colony formation assays or soft agar assays.

\section{Luciferase reporter assays}

Cells seeded into 12 well dishes were transfected with reporter plasmids expressing firefly luciferase under the control of an AP-1 responsive element using PEI or Lipofectamine 2000. Where appropriate, cells were co- transfected with a plasmid of interest, or treated as described in the figure legend. To normalise for transfection efficiency, a pRLTK Renilla luciferase reporter plasmid was added to each transfection. After $24 \mathrm{~h}$, samples were lysed in passive lysis buffer (Promega, USA) and activity measured using a dual-luciferase reporter assay system (Promega) as described [91].

\section{Western blot analysis}

Equal amounts of protein from cell lysates were separated by SDS PAGE and transferred onto a nitrocellulose membrane by a semi-dry transfer method (Trans Blot ${ }^{\circledR}$ SD Semi-Dry Transfer cell, Bio-Rad, USA). Membranes were blocked with $5 \%$ milk solution before incubation with primary antibodies at 1:1000 dilution unless otherwise stated: PhosphoSAPK/JNK (Thr183/Tyr185) (81E11; 4668, CST), SAPK/ JNK (9252, CST), Phospho-ERK1/2 (Thr202/Tyr204) (43705, CST), ERK1/2 (137F5; 4695, CST), PhosphoMAPKAP2 (Thr334) (3007, CST), MAPKAP2 (12155, CST), Phospho-c-Jun (Ser73) (D47G9; 3270, CST), c-Jun (60A8; 9165, CST), JunD (D17G2; 5000, CST), EGFR (E235; ab32077), Abcam) HPV 16/18 E6 (CBT; sc-460), HPV 16 E7 (SCBT; sc-1587), HPV 18 E7 (8E2; ab100953, Abcam), PARP-1 (9542, CST) FLAG (F1804, SigmaAldrich), GFP (B-2; sc-9996, Santa Cruz Biotechnology (SCBT)) and GAPDH (SCBT; sc365062) (1:5000) as a loading control. Horseradish peroxidase (HRP)-conjugated secondary antibodies (Sigma-Aldrich, USA) were used at a 1:5000 dilution. Proteins were detected using WesternBright ECL (Advansta, USA) and visualised on X-ray film.

\section{Chromatin immunoprecipitation}

HeLa and CaSKi cells were treated with JNK-IN-8 or transfected with a pool of c-Jun specific siRNA for the required incubation time. Cells were processed for ChIP analysis as previously described [94]. In brief, cells were fixed in $1 \%$ formaldehyde for $10 \mathrm{~min}$ at room temperature, quenched in $0.25 \mathrm{M}$ glycine, and washed in ice-cold PBS. Cells were harvested by scraping and then lysed in cell lysis buffer (10 mM Tris-HCl, pH 8.0, $10 \mathrm{mM} \mathrm{NaCl}, 0.2 \%$ NP-40, $10 \mathrm{mM}$ sodium butyrate, $50 \mu \mathrm{g} / \mathrm{ml}$ phenylmethylsulfonyl fluoride (PMSF), $1 \times$ complete protease inhibitor). Nuclei were collected by centrifugation at $2500 \mathrm{rpm}$ at $4{ }^{\circ} \mathrm{C}$ and resuspended in nuclear lysis buffer $(50 \mathrm{mM}$ Tris- $\mathrm{HCl}, \mathrm{pH} 8.1$, $10 \mathrm{mM}$ EDTA, $1 \%$ SDS, $10 \mathrm{mM}$ sodium butyrate, $50 \mu \mathrm{g} / \mathrm{ml}$ PMSF, $1 \times$ complete protease inhibitor). Extracted chromatin was then sonicated and chromatin concentration was determined. Approximately $100 \mu \mathrm{g}$ of chromatin from each sample was used for the experiment. c-Jun was immunoprecipitated using a ChIP grade anti-c-Jun antibody (60A8; 9165, CST). $\mathrm{A} / \mathrm{G}$ magnetic beads were used to pull down the antibody- 
chromatin complex. To show antibody specificity, each of the samples was pulled down with an IgG isotype control. The immunoprecipitated chromatin was then processed for quantitative PCR (qPCR); the primer sequences used are available on request. Fold-enrichment compared to negative control IgG isotype control was calculated as in [95].

\section{RNA extraction, CDNA synthesis and quantitative real Time-PCR}

RNA extraction for qRT-PCR was performed using an E.Z. N.A Total RNA Kit I (Omega bio-tek, USA). cDNA was synthesised with $1 \mu \mathrm{g}$ of input RNA and iScript cDNA synthesis kit (Bio Rad, USA). qRT-PCR was performed on the synthesised cDNA on a Corbett Rotor-Gene 6000 using QuantiFast SYBR Green PCR kit (Qiagen, USA) and analysed using the $\Delta \Delta C T$ method [96] normalised to the $U 6$ housekeeping gene. Primer sequences are available on request.

\section{Colony formation assay}

Forty-eight or 72-h post-treatment or transfection, cells were trypsinised and reseeded in a six-well plate at 500 cells per well and left to incubate for 14-21 days. Colonies were then stained (1\% crystal violet, $25 \%$ methanol) and colonies were counted manually. Each experiment was repeated a minimum of three times.

\section{Soft agar assay}

Cells were treated or transfected as required. Sixty millimetre dishes were coated with a layer of $1 \%$ agarose (ThermoFisher Scientific) in $2 \times$ DMEM (ThermoFisher Scientific) supplemented with $20 \%$ FBS. Forty-eight hours post-transfection, cells were trypsinised and added to $0.7 \%$ agarose in $2 \times$ DMEM (ThermoFisher Scientific) supplemented with $20 \%$ FBS at 1000 cells $/ \mathrm{mL}$. Once set, DMEM supplemented with $10 \%$ FBS and $50 \mathrm{U} / \mathrm{mL}$ penicillin was added. The plates were then incubated for 14-21 days. Each experiment was repeated at least three times. Visible colonies were counted manually.

\section{Flow cytometry}

Cells were treated or transfected as required. 48 or $72-\mathrm{h}$ post-transfection, cells were harvested and fixed in $70 \%$ ethanol overnight. The ethanol was removed, and cells washed with PBS containing $0.5 \%(\mathrm{w} / \mathrm{v}) \mathrm{BSA}$. Cells were stained with PBS containing $0.5 \%$ BSA, $50 \mu \mathrm{g} / \mathrm{mL}$ propidium iodide (Sigma-Aldrich) and $5 \mu \mathrm{g} / \mathrm{mL}$ RNase (SigmaAldrich) and incubated for $30 \mathrm{~min}$ at room temperature. Samples were processed on a CytoFLEX S flow cytometer
(Beckman Coulter) and analysed using CytExpert (Beckman Coulter).

\section{Annexin V assay}

Annexin V apoptosis assay (TACS Annexin V kit; 4830250-K) was performed as indicated on the product datasheet. In brief, cells seeded in 6-well plates were treated or transfected as required. Cells were trypsinised and collected by centrifugation. $1 \times 10^{6}$ cells were then incubated in $100 \mu \mathrm{L}$ Annexin V reagent $(10 \mu \mathrm{L} 10 \times$ binding buffer, $10 \mu \mathrm{L}$ propidium iodide, $1 \mu \mathrm{L}$ Annexin V-FITC (diluted 1 in 500 ) and $79 \mu \mathrm{L} \mathrm{ddH2O)} \mathrm{for} 15 \mathrm{~min}$ at room temperature in the dark. Samples were diluted in $1 \times$ binding buffer before analysis by flow cytometry. Samples were processed on a CytoFLEX S flow cytometer (Beckman Coulter) and analysed using CytExpert (Beckman Coulter).

\section{TCPA data analysis}

RPPA data from the Cancer Genome Atlas (TCGA) was downloaded via The Cancer Proteome Atlas (TCPA) online repository [37, 38]. Correlation between Phospho-SAPK/ JNK (Thr183/Tyr185), Phospho-ERK1/2 (Thr202/Tyr204) and Phospho-p38 (Thr180/Tyr182) with the substrate Phospho-c-Jun (Ser73) was assessed.

\section{Statistical analysis}

Data points from at least three individual, biological repeats are shown in each graph. Unless otherwise indicated in the figure legends, data were analysed using a two-tailed, unpaired Student's $t$-test and graphs were prepared using the GraphPad Prism software (GraphPad, USA). Error bars represent the mean $+/-$ standard deviation. Statistical significance was determined as follows: $* P<0.05, * * P<0.01$, $* * * P<0.001$. Survival analysis was performed using the Kaplan-Meier method with the log-rank test (univariate).

\section{Funding}

This work was supported by Medical Research Council (MRC) funding to AM (MR/ K012665 and MR/S001697/ 1). ELM has received support from a Wellcome Trust studentship (1052221/Z/14/Z) and the Wellcome Institutional Strategic Support Fund (ISSF) (204825/Z/16/Z). MRP is funded by Biotechnology and Biological Sciences Research Council studentships (BB/M011151/1). JAS is funded by a Faculty of Biological Sciences, University of Leeds scholarship. The funders had no role in study design, data collection and analysis, decision to publish, or preparation of the manuscript. 
Acknowledgements We are particularly grateful to Prof. Roger Davis (UMASS, United States) for the generous provision of reagents through the Addgene repository. We additionally thank Prof. Felix Hoppe-Seyler (German Cancer Research Center, Heidelberg, Germany), Dr Nicholas Wallace (Kansas State University, USA) and Prof. Simon Arthur (University of Dundee, UK) for the provision of plasmids. We thank the Scottish HPV Investigators Network (SHINE) for providing HPV positive cytology samples. Finally, we thank Dr Stephen Griffin (University of Leeds, UK) for critical reading of the manuscript.

\section{Compliance with ethical standards}

Conflict of interest The authors declare that they have no conflict of interest.

Publisher's note Springer Nature remains neutral with regard to jurisdictional claims in published maps and institutional affiliations.

Open Access This article is licensed under a Creative Commons Attribution 4.0 International License, which permits use, sharing, adaptation, distribution and reproduction in any medium or format, as long as you give appropriate credit to the original author(s) and the source, provide a link to the Creative Commons license, and indicate if changes were made. The images or other third party material in this article are included in the article's Creative Commons license, unless indicated otherwise in a credit line to the material. If material is not included in the article's Creative Commons license and your intended use is not permitted by statutory regulation or exceeds the permitted use, you will need to obtain permission directly from the copyright holder. To view a copy of this license, visit http://creativecommons. org/licenses/by/4.0/.

\section{References}

1. Hausen zur H. Papillomaviruses and cancer: from basic studies to clinical application. Nat Rev Cancer. 2002;2:342-50.

2. Crosbie EJ, Einstein MH, Franceschi S, Kitchener HC. Human papillomavirus and cervical cancer. Lancet. 2013;382:889-99.

3. Zhang B, Srirangam A, Potter DA, Roman A. HPV16 E5 protein disrupts the c-Cbl-EGFR interaction and EGFR ubiquitination in human foreskin keratinocytes. Oncogene. 2005;24:2585-8.

4. Purpura V, Belleudi F, Caputo S, Torrisi MR. HPV16 E5 and KGFR/FGFR2b interplay in differentiating epithelial cells. Oncotarget. 2013;4:192-205.

5. Wasson CW, Morgan EL, Müller M, Ross RL, Hartley M, Roberts S, et al. Human papillomavirus type 18 E5 oncogene supports cell cycle progression and impairs epithelial differentiation by modulating growth factor receptor signalling during the virus life cycle. Oncotarget. 2017;8:103581-600.

6. Miyauchi S, Sanders PD, Guram K, Kim SS, Paolini F, Venuti A, et al. HPV16 E5 Mediates Resistance to PD-L1 Blockade and Can Be Targeted with Rimantadine in Head and Neck Cancer. Cancer Res. 2020;80:732-46.

7. Scheffner M, Huibregtse JM, Vierstra RD, Howley PM. The HPV-16 E6 and E6-AP complex functions as a ubiquitin-protein ligase in the ubiquitination of p53. Cell. 1993;75:495-505.

8. Boyer SN, Wazer DE, Band V. E7 protein of human papilloma virus-16 induces degradation of retinoblastoma protein through the ubiquitin-proteasome pathway. Cancer Res. 1996;56:4620-4.

9. Pim D, Massimi P, Dilworth SM, Banks L. Activation of the protein kinase B pathway by the HPV-16 E7 oncoprotein occurs through a mechanism involving interaction with PP2A. Oncogene. 2005;24:7830-8.
10. Contreras-Paredes A, la Cruz-Hernández DeE, Martínez-Ramírez I, Dueñas-Gonzalez A, Lizano M. E6 variants of human papillomavirus 18 differentially modulate the protein kinase $\mathrm{B} /$ phosphatidylinositol 3-kinase (akt/PI3K) signaling pathway. Virology. 2009;383:78-85.

11. Bello JOM, Nieva LO, Paredes AC, Gonzalez AMF, Zavaleta LR, Lizano M. Regulation of the Wnt/ $\beta$-catenin signaling pathway by human papillomavirus E6 and E7 oncoproteins. Viruses. 2015;7:4734-55.

12. He C, Mao D, Hua G, Lv X, Chen X, Angeletti PC, et al. The Hippo/YAP pathway interacts with EGFR signaling and HPV oncoproteins to regulate cervical cancer progression. EMBO Mol Med. 2015;7:1426-49.

13. Morgan EL, Macdonald A. Autocrine STAT3 activation in HPV positive cervical cancer through a virus-driven Rac1-NFkB-IL-6 signalling axis. PLoS Pathog. 2019;15:e1007835.

14. Morgan EL, Macdonald A. JAK2 inhibition impairs proliferation and sensitises cervical cancer cells to cisplatin-induced cell death. Cancers. 2019;11:1934.

15. Morgan EL, Patterson MR, Ryder EL, Lee SY, Wasson CW, Harper KL, et al. MicroRNA-18a targeting of the STK4/MST1 tumour suppressor is necessary for transformation in HPV positive cervical cancer. PLoS Pathog. 2020;16:e1008624.

16. Lee S, Rauch J, Kolch W. Targeting MAPK signaling in cancer: mechanisms of drug resistance and sensitivity. Int $\mathrm{J}$ Mol Sci. 2020;21:1102.

17. Satsuka A, Mehta K, Laimins L. p38MAPK and MK2 pathways are important for the differentiation-dependent human papillomavirus life cycle. J Virol. 2015;89:1919-24.

18. Egawa N, Wang Q, Griffin HM, Murakami I, Jackson D, Mahmood R, et al. HPV16 and 18 genome amplification show different E4-dependence, with 16E4 enhancing E1 nuclear accumulation and replicative efficiency via its cell cycle arrest and kinase activation functions. PLoS Pathog. 2017;13:e1006282.

19. Wetherill LF, Wasson CW, Swinscoe G, Kealy D, Foster R, Griffin S, et al. Alkyl-imino sugars inhibit the pro-oncogenic ion channel function of human papillomavirus (HPV) E5. Antivir Res. 2018;158:113-21.

20. Weston CR, Davis RJ. The JNK signal transduction pathway. Curr Opin Cell Biol. 2007;19:142-9.

21. Tournier C. The 2 faces of JNK signaling in cancer. Genes Cancer. 2013;4:397-400.

22. Xiao L, Lang W. A dominant role for the c-Jun NH2-terminal kinase in oncogenic ras-induced morphologic transformation of human lung carcinoma cells. Cancer Res. 2000;60:400-8.

23. Kennedy NJ, Sluss HK, Jones SN, Bar-Sagi D, Flavell RA, Davis RJ. Suppression of Ras-stimulated transformation by the JNK signal transduction pathway. Genes Dev. 2003;17:629-37.

24. Cellurale C, Sabio G, Kennedy NJ, Das M, Barlow M, Sandy P, et al. Requirement of c-Jun $\mathrm{NH}(2)$-terminal kinase for Rasinitiated tumor formation. Mol Cell Biol. 2011;31:1565-76.

25. Raitano AB, Halpern JR, Hambuch TM, Sawyers CL. The Bcr-Abl leukemia oncogene activates Jun kinase and requires Jun for transformation. Proc Natl Acad Sci USA. 1995;92: 11746-50.

26. Vivanco I, Palaskas N, Tran C, Finn SP, Getz G, Kennedy NJ, et al. Identification of the JNK signaling pathway as a functional target of the tumor suppressor PTEN. Cancer Cell. 2007;11: 555-69.

27. Xie X, Kaoud TS, Edupuganti R, Zhang T, Kogawa T, Zhao Y, et al. c-Jun N-terminal kinase promotes stem cell phenotype in triple-negative breast cancer through upregulation of Notch1 via activation of c-Jun. Oncogene. 2017;36:2599-608.

28. Girnius N, Edwards YJ, Garlick DS, Davis RJ. The cJUN NH2terminal kinase (JNK) signaling pathway promotes genome stability and prevents tumor initiation. Elife. 2018;7:27. 
29. Morgan EL, Wasson CW, Hanson L, Kealy D, Pentland I, McGuire V, et al. STAT3 activation by E6 is essential for the differentiation-dependent HPV18 life cycle. PLoS Pathog. 2018;14:e1006975.

30. Ghittoni R, Accardi R, Chiocca S, Tommasino M. Role of human papillomaviruses in carcinogenesis. Ecancermedicalscience. 2015;9:526.

31. Bogoyevitch MA, Kobe B. Uses for JNK: the many and varied substrates of the c-Jun N-terminal kinases. Microbiol Mol Biol Rev. 2006;70:1061-95.

32. Zenz R, Scheuch H, Martin P, Frank C, Eferl R, Kenner L, et al. cJun regulates eyelid closure and skin tumor development through EGFR signaling. Dev Cell. 2003;4:879-89.

33. Zhang JY, Selim MA. The role of the c-Jun N-terminal Kinase signaling pathway in skin cancer. Am J Cancer Res. 2012;2:691-8.

34. Pulverer BJ, Kyriakis JM, Avruch J, Nikolakaki E, Woodgett JR. Phosphorylation of c-jun mediated by MAP kinases. Nature 1991;353:670-4.

35. Morton S, Davis RJ, McLaren A, Cohen P. A reinvestigation of the multisite phosphorylation of the transcription factor c-Jun. EMBO J. 2003;22:3876-86.

36. Humar $M$, Loop $T$, Schmidt $R$, Hoetzel A, Roesslein $M$, Andriopoulos $\mathrm{N}$, et al. The mitogen-activated protein kinase $\mathrm{p} 38$ regulates activator protein 1 by direct phosphorylation of c-Jun. Int J Biochem Cell Biol. 2007;39:2278-88.

37. Li J, Akbani R, Zhao W, Lu Y, Weinstein JN, Mills GB, et al. Explore, visualize, and analyze functional cancer proteomic data using the cancer proteome atlas. Cancer Res. 2017;77:e51-4.

38. Chen M-JM, Li J, Wang Y, Akbani R, Lu Y, Mills GB, et al. TCPA v3.0: an integrative platform to explore the pan-cancer analysis of functional proteomic data. Mol Cell Proteom. 2019;18: S15-25.

39. Kho E-Y, Wang H-K, Banerjee NS, Broker TR, Chow LT. HPV18 E6 mutants reveal p53 modulation of viral DNA amplification in organotypic cultures. Proc Natl Acad Sci USA. 2013;110:7542-9.

40. Huibregtse JM, Scheffner M, Howley PM. Localization of the E6AP regions that direct human papillomavirus E6 binding, association with $\mathrm{p} 53$, and ubiquitination of associated proteins. Mol Cell Biol. 1993;13:4918-27.

41. Delury CP, Marsh EK, James CD, Boon SS, Banks L, Knight GL, et al. The role of protein kinase A regulation of the E6 PDZbinding domain during the differentiation-dependent life cycle of human papillomavirus type 18. J Virol. 2013;87:9463-72.

42. Bennett BL, Sasaki DT, Murray BW, O'Leary EC, Sakata ST, Xu W, et al. SP600125, an anthrapyrazolone inhibitor of Jun Nterminal kinase. Proc Natl Acad Sci USA. 2001;98:13681-6.

43. Zhang $\mathrm{T}$, Inesta-Vaquera $\mathrm{F}$, Niepel $\mathrm{M}$, Zhang $\mathrm{J}$, Ficarro $\mathrm{SB}$, Machleidt T, et al. Discovery of potent and selective covalent inhibitors of JNK. Chem Biol. 2012;19:140-54.

44. Angel P, Hattori K, Smeal T, Karin M. The jun proto-oncogene is positively autoregulated by its product, Jun/AP-1. Cell. 1988;55:875-85.

45. Chen N, Nomura M, She QB, Ma WY, Bode AM, Wang L, et al. Suppression of skin tumorigenesis in c-Jun $\mathrm{NH}(2)$-terminal kinase-2-deficient mice. Cancer Res. 2001;61:3908-12.

46. She Q-B, Chen N, Bode AM, Flavell RA, Dong Z. Deficiency of c-Jun-NH(2)-terminal kinase-1 in mice enhances skin tumor development by 12-O-tetradecanoylphorbol-13-acetate. Cancer Res. 2002;62:1343-8.

47. Gupta S, Barrett T, Whitmarsh AJ, Cavanagh J, Sluss HK, Dérijard B, et al. Selective interaction of JNK protein kinase isoforms with transcription factors. EMBO J. 1996;15:2760-70.

48. Liu X, Li H, Rajurkar M, Li Q, Cotton JL, Ou J, et al. Tead and AP1 coordinate transcription and motility. Cell Rep. 2016;14:1169-80.
49. Chemoradiotherapy for Cervical Cancer Meta-Analysis Collaboration. Reducing uncertainties about the effects of chemoradiotherapy for cervical cancer: a systematic review and metaanalysis of individual patient data from 18 randomized trials. J Clin Oncol. 2008;26:5802-12.

50. Qureshi R, Arora H, Rizvi MA. EMT in cervical cancer: its role in tumour progression and response to therapy. Cancer Lett. 2015;356:321-31

51. Alcorn JF, Guala AS, van der Velden J, McElhinney B, Irvin CG, Davis RJ, et al. Jun N-terminal kinase 1 regulates epithelial-tomesenchymal transition induced by TGF-beta1. J Cell Sci. 2008;121:1036-45.

52. Sahu SK, Garding A, Tiwari N, Thakurela S, Toedling J, Gebhard $\mathrm{S}$, et al. JNK-dependent gene regulatory circuitry governs mesenchymal fate. EMBO J. 2015;34:2162-81.

53. Li G, Gustafson-Brown C, Hanks SK, Nason K, Arbeit JM, Pogliano K, et al. c-Jun is essential for organization of the epidermal leading edge. Dev Cell. 2003;4:865-77.

54. Mine N, Iwamoto R, Mekada E. HB-EGF promotes epithelial cell migration in eyelid development. Development. 2005;132: 4317-26.

55. Mialon A, Sankinen M, Söderström H, Junttila TT, Holmström T, Koivusalo R, et al. DNA topoisomerase I is a cofactor for c-Jun in the regulation of epidermal growth factor receptor expression and cancer cell proliferation. Mol Cell Biol. 2005;25:5040-51.

56. Wang F, Liu R, Lee SW, Sloss CM, Couget J, Cusack JC. Heparin-binding EGF-like growth factor is an early response gene to chemotherapy and contributes to chemotherapy resistance. Oncogene. 2007;26:2006-16.

57. Fang Y, Wang Y, Wang Y, Meng Y, Zhu J, Jin H, et al. A new tumour suppression mechanism by p27Kip1: EGFR downregulation mediated by $\mathrm{JNK} / \mathrm{c}-\mathrm{Jun}$ pathway inhibition. Biochem J. 2014;463:383-92.

58. Spangle JM, Münger K. The HPV16 E6 oncoprotein causes prolonged receptor protein tyrosine kinase signaling and enhances internalization of phosphorylated receptor species. PLoS Pathog. 2013;9:e1003237.

59. DeFilippis RA, Goodwin EC, Wu L, DiMaio D. Endogenous human papillomavirus E6 and E7 proteins differentially regulate proliferation, senescence, and apoptosis in HeLa cervical carcinoma cells. J Virol. 2003;77:1551-63.

60. Butz K, Hoppe-Seyler F. Transcriptional control of human papillomavirus (HPV) oncogene expression: composition of the HPV type 18 upstream regulatory region. J Virol. 1993;67: 6476-86.

61. Kyo S, Tam A, Laimins LA. Transcriptional activity of human papillomavirus type $31 \mathrm{~b}$ enhancer is regulated through synergistic interaction of AP1 with two novel cellular factors. Virology 1995;211:184-97.

62. Rösl F, Das BC, Lengert M, Geletneky K, Hausen zur H. Antioxidant-induced changes of the AP-1 transcription complex are paralleled by a selective suppression of human papillomavirus transcription. J Virol. 1997;71:362-70.

63. Talora C, Sgroi DC, Crum CP, Dotto GP. Specific downmodulation of Notch1 signaling in cervical cancer cells is required for sustained HPV-E6/E7 expression and late steps of malignant transformation. Genes Dev. 2002;16:2252-63.

64. De-Castro Arce J, Soto U, van Riggelen J, Schwarz E, Hausen zur $\mathrm{H}$, Rösl F. Ectopic expression of nonliganded retinoic acid receptor beta abrogates AP-1 activity by selective degradation of c-Jun in cervical carcinoma cells. J Biol Chem. 2004;279: 45408-16.

65. De-Castro Arce J, Göckel-Krzikalla E, Rösl F. Retinoic acid receptor beta silences human papillomavirus-18 oncogene expression by induction of de novo methylation and 
heterochromatinization of the viral control region. J Biol Chem. 2007;282:28520-9.

66. Schumann S, Jackson BR, Yule I, Whitehead SK, Revill C, Foster $\mathrm{R}$, et al. Targeting the ATP-dependent formation of herpesvirus ribonucleoprotein particle assembly as an antiviral approach. Nat Microbiol. 2016;2:16201.

67. Brand TM, Hartmann S, Bhola NE, Peyser ND, Li H, Zeng Y, et al. Human papillomavirus regulates her3 expression in head and neck cancer: implications for targeted HER3 therapy in HPV+ patients. Clin Cancer Res. 2017;23:3072-83.

68. Bahrami A, Hasanzadeh M, Hassanian SM, ShahidSales S, Ghayour-Mobarhan M, Ferns GA, et al. The potential value of the PI3K/Akt/mTOR signaling pathway for assessing prognosis in cervical cancer and as a target for therapy. J Cell Biochem. 2017;118:4163-9.

69. He C, Mao D, Hua G, Lv X, Chen X, Angeletti PC, et al. The Hippo/YAP pathway interacts with EGFR signaling and HPV oncoproteins to regulate cervical cancer progression. EMBO Mol Med. 2015;7:1426-49.

70. Rodrigues GA, Park M, Schlessinger J. Activation of the JNK pathway is essential for transformation by the Met oncogene. EMBO J. 1997;16:2634-45.

71. Zhao L, Wang L, Zhang C, Liu Z, Piao Y, Yan J, et al. E6-induced selective translation of WNT4 and JIP2 promotes the progression of cervical cancer via a noncanonical WNT signaling pathway. Signal Transduct Target Ther. 2019;4:32.

72. Eferl R, Wagner EF. AP-1: a double-edged sword in tumorigenesis. Nat Rev Cancer. 2003;3:859-68.

73. de Wilde J, De-Castro Arce J, Snijders PJF, Meijer CJLM, Rösl F, Steenbergen RDM. Alterations in AP-1 and AP-1 regulatory genes during HPV-induced carcinogenesis. Cell Oncol. 2008;30:77-87.

74. Mahata S, Bharti AC, Shukla S, Tyagi A, Husain SA, Das BC. Berberine modulates AP-1 activity to suppress HPV transcription and downstream signaling to induce growth arrest and apoptosis in cervical cancer cells. Mol Cancer. 2011;10:39-14.

75. Kuntzen C, Sonuc N, De Toni EN, Opelz C, Mucha SR, Gerbes $\mathrm{AL}$, et al. Inhibition of c-Jun-N-terminal-kinase sensitizes tumor cells to CD95-induced apoptosis and induces G2/M cell cycle arrest. Cancer Res. 2005;65:6780-8. 1

76. Moon DO, Kim MO, Kang CH, Lee JD, Choi YH, Kim GY. JNK inhibitor SP600125 promotes the formation of polymerized tubulin, leading to G2/M phase arrest, endoreduplication, and delayed apoptosis. Exp Mol Med. 2009;41:665-77.

77. Mili D, Abid K, Rjiba I, Kenani A. Effect of SP600125 on the mitotic spindle in HeLa Cells, leading to mitotic arrest, endoreduplication and apoptosis. Mol Cytogenet. 2016;9:86-7.

78. Weston CR, Wong A, Hall JP, Goad MEP, Flavell RA, Davis RJ. The c-Jun NH2-terminal kinase is essential for epidermal growth factor expression during epidermal morphogenesis. Proc Natl Acad Sci USA. 2004;101:14114-9.

79. Meixner A, Karreth F, Kenner L, Penninger JM, Wagner EF. Jun and JunD-dependent functions in cell proliferation and stress response. Cell Death Differ. 2010;17:1409-19.

80. Wang LM, Kuo A, Alimandi M, Veri MC, Lee CC, Kapoor V, et al. ErbB2 expression increases the spectrum and potency of ligand-mediated signal transduction through ErbB4. Proc Natl Acad Sci USA. 1998;95:6809-14.

81. Zhang E, Feng X, Liu F, Zhang P, Liang J, Tang X. Roles of $\mathrm{PI} 3 \mathrm{~K} / \mathrm{Akt}$ and c-Jun signaling pathways in human papillomavirus type 16 oncoprotein-induced HIF-1 $\alpha$, VEGF, and IL- 8 expression and in vitro angiogenesis in non-small cell lung cancer cells. PLoS ONE. 2014;9:e103440.

82. Thomas M, Narayan N, Pim D, Tomaić V, Massimi P, Nagasaka $\mathrm{K}$, et al. Human papillomaviruses, cervical cancer and cell polarity. Oncogene. 2008;27:7018-30.

83. Igaki T, Pagliarini RA, Xu T. Loss of cell polarity drives tumor growth and invasion through JNK activation in Drosophila. Curr Biol. 2006;16:1139-46.

84. Padash Barmchi M, Gilbert M, Thomas M, Banks L, Zhang B, Auld VJ. A Drosophila model of HPV E6-induced malignancy reveals essential roles for magi and the insulin receptor. PLoS Pathog. 2016;12:e1005789.

85. Cripe TP, Alderborn A, Anderson RD, Parkkinen S, Bergman P, Haugen $\mathrm{TH}$, et al. Transcriptional activation of the human papillomavirus-16 $\mathrm{P} 97$ promoter by an 88-nucleotide enhancer containing distinct cell-dependent and AP-1-responsive modules. N Biol. 1990;2:450-63.

86. Peto M, Tolle-Ersü I, Kreysch HG, Klock G. Epidermal growth factor induction of human papillomavirus type 16 E6/E7 MRNA in tumor cells involves two AP-1 binding sites in the viral enhancer. J Gen Virol. 1995;76:1945-58.

87. Gaiotti D, Chung J, Iglesias M, Nees M, Baker PD, Evans CH, et al. Tumor necrosis factor-alpha promotes human papillomavirus (HPV) E6/E7 RNA expression and cyclin-dependent kinase activity in HPV-immortalized keratinocytes by a ras-dependent pathway. Mol Carcinog. 2000;27:97-109.

88. Varghese F, Bukhari AB, Malhotra R, De A. IHC Profiler: an open source plugin for the quantitative evaluation and automated scoring of immunohistochemistry images of human tissue samples. PLoS ONE. 2014;9:e96801.

89. Detre S, Saclani Jotti G, Dowsett MA. "quickscore" method for immunohistochemical semiquantitation: validation for oestrogen receptor in breast carcinomas. J Clin Pathol. 1995;48:876-8.

90. Knight GL, Pugh AG, Yates E, Bell I, Wilson R, Moody CA, et al. A cyclin-binding motif in human papillomavirus type 18 (HPV18) E1^E4 is necessary for association with CDK-cyclin complexes and G2/M cell cycle arrest of keratinocytes, but is not required for differentiation-dependent viral genome amplification or L1 capsid protein expression. Virology. 2011;412:196-210.

91. Macdonald A, Mazaleyrat S, McCormick C, Street A, Burgoyne NJ, Jackson RM, et al. Further studies on hepatitis C virus NS5A$\mathrm{SH} 3$ domain interactions: identification of residues critical for binding and implications for viral RNA replication and modulation of cell signalling. J Gen Virol. 2005;86:1035-44.

92. Jiang M, Milner J. Selective silencing of viral gene expression in HPV-positive human cervical carcinoma cells treated with siRNA, a primer of RNA interference. Oncogene. 2002;21:6041-8.

93. Hall AHS, Alexander KA. RNA interference of human papillomavirus type 18 E6 and E7 induces senescence in HeLa cells. J Virol. 2003;77:6066-9.

94. Das D, Bristol ML, Smith NW, James CD, Wang X, Pichierri P, et al. Werner helicase control of human papillomavirus 16 E1-E2 DNA replication is regulated by SIRT1 deacetylation. MBio. 2019;10:260.

95. Pentland I, Campos-León K, Cotic M, Davies K-J, Wood CD, Groves IJ, et al. Disruption of CTCF-YY1-dependent looping of the human papillomavirus genome activates differentiation-induced viral oncogene transcription. PLoS Biol. 2018;16:e2005752.

96. Livak KJ, Schmittgen TD. Analysis of relative gene expression data using real-time quantitative PCR and the 2(-delta delta C(T)) method. Methods. 2001;25:402-8. 